\title{
Hydrogen Peroxide and Polyamines Act as Double Edged Swords in Plant Abiotic Stress Responses
}

\author{
Kamala Gupta ${ }^{1,2 *}$, Atreyee Sengupta ${ }^{1 \dagger}$, Mayukh Chakraborty ${ }^{1 \dagger}$ and Bhaskar Gupta ${ }^{1,3 *}$ \\ ${ }^{1}$ Department of Biological Sciences, Presidency University, Kolkata, India, ${ }^{2}$ Department of Botany, Government General \\ Degree College, Affiliated to University of Burdwan, Singur, India, ${ }^{3}$ Department of Zoology, Government General Degree \\ College, Affiliated to University of Burdwan, Singur, India
}

\section{OPEN ACCESS}

Edited by:

Sarvajeet Singh Gill,

Maharshi Dayanand University, India

Reviewed by:

Vasileios Fotopoulos,

Cyprus University of Technology,

Cyprus

Mirza Hasanuzzaman, Sher-e-Bangla Agricultural University,

Bangladesh

${ }^{*}$ Correspondence: Kamala Gupta kamalagupta@gmail.com Bhaskar Gupta

bhaskarzoology@gmail.com

${ }^{\dagger}$ These authors have contributed equally to this work.

Specialty section:

This article was submitted to

Plant Physiology,

a section of the journal

Frontiers in Plant Science

Received: 27 March 2016

Accepted: 22 August 2016

Published: 12 September 2016

Citation:

Gupta K, Sengupta A, Chakraborty M and Gupta B (2016) Hydrogen

Peroxide and Polyamines Act as Double Edged Swords in Plant Abiotic

Stress Responses.

Front. Plant Sci. 7:1343. doi: 10.3389/fpls.2016.01343
The specific genetic changes through which plants adapt to the multitude of environmental stresses are possible because of the molecular regulations in the system. These intricate regulatory mechanisms once unveiled will surely raise interesting questions. Polyamines and hydrogen peroxide have been suggested to be important signaling molecules during biotic and abiotic stresses. Hydrogen peroxide plays a versatile role from orchestrating physiological processes to stress response. It helps to achieve acclimatization and tolerance to stress by coordinating intra-cellular and systemic signaling systems. Polyamines, on the other hand, are low molecular weight polycationic aliphatic amines, which have been implicated in various stress responses. It is quite interesting to note that both hydrogen peroxide and polyamines have a fine line of inter-relation between them since the catabolic pathways of the latter releases hydrogen peroxide. In this review we have tried to illustrate the roles and their multifaceted functions of these two important signaling molecules based on current literature. This review also highlights the fact that over accumulation of hydrogen peroxide and polyamines can be detrimental for plant cells leading to toxicity and pre-mature cell death.

Keywords: polyamines, hydrogen peroxide $\left(\mathrm{H}_{2} \mathrm{O}_{2}\right)$, reactive oxygen species (ROS), nitric oxide (NO), abscisic acid (ABA), abiotic stress tolerance

\section{INTRODUCTION}

Life and stress go hand in hand for all living organisms but in case of plants, being sedentary organisms, stress has to be dealt with in a special way. Plants are subjected to constant environment changes forcing them to fine tune their metabolic processes in order to maintain a steady state balance of the energy production and consumption. A dedicated-signaling network influencing the three main metabolic processes-photosynthesis, respiration, and photorespiration-help in overcoming the imbalance, thereby maintaining growth, and productivity. The main fallout of metabolic imbalance is oxidative stress caused due to the excess production of reactive oxygen species (ROS). Therefore, in order to maintain normal growth and development the plants orchestrate a myriad of stress responsive metabolites like proline and polyamines, along with several antioxidative enzymes, that help to detoxify the ROS. Recent studies have also revealed the capability of ROS to act as signaling molecules in activating defense responses (reviewed by Gill and Tuteja, 2010; Gupta et al., 2013a; Pál et al., 2015; Saha et al., 2015). Thus, ROS are considered nowadays as not only toxic byproducts of aerobic metabolism with strictly controlled cellular levels, but they also function as signaling agents regulating many biological processes and producing pleiotropic effects (Gadjev et al., 2008; Mittler et al., 2011). 
Polyamines-putrescine, spermidine, and spermine-which are present in multitude of living organisms are a group of low molecular weight polycations with diverse physiological and developmental functions essential for events such as senescence and stress responses (Roy et al., 2005; Gupta et al., 2014; Nahar et al., 2016). Counterbalancing cellular levels of ROS, in order to maintain a healthy environment for the cells to thrive, is one of the major roles played by polyamines (Miller et al., 2010; Saha et al., 2015). Hydrogen peroxide $\left(\mathrm{H}_{2} \mathrm{O}_{2}\right)$ is one of the key ROS molecules produced in living cells from various internal sources. Particularly in plants, the major processes that lead to the production of $\mathrm{H}_{2} \mathrm{O}_{2}$ involve photorespiration or $\mathrm{C}_{2}$ cycle, which includes three different organelles-chloroplast, mitochondria, and peroxisome. Of these, mitochondrial and chloroplastidial electron transport chain and oxidation of fatty acids in the mitochondrial matrix play a major role in contributing to the $\mathrm{H}_{2} \mathrm{O}_{2}$ pool within the cell. In addition, pathogenic infections might also induce an oxidative stress leading to oxidative burst. In fact both the production and scavenging of $\mathrm{H}_{2} \mathrm{O}_{2}$ act in synchrony to tide out plants during stress conditions (Miller et al., 2010).

The paradox of $\mathrm{H}_{2} \mathrm{O}_{2}$ physiology is indeed an interesting one-on one hand at lower concentrations it initiates various intra cellular signaling activities while at higher concentrations it is malevolent for the cellular metabolites (Gechev and Hille, 2005; Bhattacharjee, 2012). ROS levels when too high might lead to metabolic dysfunctioning of plant cells and at the same time induce nucleic acid, protein, and lipid damages (Anjum et al., 2015). To combat oxidative stress, plants produce metabolites and molecules like polyamines and $\mathrm{H}_{2} \mathrm{O}_{2}$ (Mittler et al., 2011). Sub-cellular organelles like the mitochondria and chloroplasts are also key regulators in the sense that alterations in carbon metabolism during stress in these compartments also help in metabolic coordination to avoid excessive generation of ROS and oxidative damage (Takahashi and Murata, 2008; Baxter et al., 2014).

The focus of this review is to decipher the roles of the two important players $-\mathrm{H}_{2} \mathrm{O}_{2}$ and polyamine-either antagonistic or agonistic or both and to try to elucidate a relationship between them, which eventually modulate the signaling cascades that are initiated in response to abiotic stress.

\section{ROS AND POLYAMINES-KEY PLAYERS IN ABIOTIC STRESS RESPONSE}

In this modern era of food security, the ever-increasing level of population demands a robust scientific approach for proper harvest and increase of food crops. From drought to salt and metal toxicity to temperature-stress conditions are omnipresent and have to be dealt with properly without creating any adverse effect on the essential metabolome. The crop productivity of the entire world in this era of food security remains a matter of great concern. It has been observed for a long time that most damage to crop plants in fields occur when two or more stresses are prevailing (Mittler, 2006). Most recent studies indicate that the plant's responses to two or more factors are unique and differ from the response to one factor only. For example, subjecting the plants to only drought stress leads to high content of proline, but subjecting the same species to drought combined with high temperature leads to high content of sucrose and other sugars, but not proline. Hence, Mittler (2006), studying all prevailing abiotic factor has suggested treating this situation as a new stress condition that he called "stress combination." Several studies have established the role of ROS as a key signaling molecule in initiating defense mechanism in response to environmental stresses and pathogen infections by modulating pathways involved in different developmental processes and programmed cell death (PCD) (Mittler et al., 2011; Baxter et al., 2014). Different abiotic stress factors such as drought and salinity have been found to augment the production of ROS and lead to ROS-associated injury (Miao et al., 2006; Abbasi et al., 2007; Zhu et al., 2007; Giraud et al., 2008). ROS scavenging properties have also been identified by the increased cellular accumulation of sugar alcohols such as mannitol, sorbitol, and inositol. Transgenic tobacco with increased mannitol concentration confers protection to the cell from oxidative damages by increasing its scavenging capacity. Moreover, mannitol accumulations do not show any deleterious effect on plants, thus proving that sugar does not show any malicious feedback (Bolouri-Moghaddam et al., 2010). Intensity of light has also remained a potent stress for plants and the triggering of common pathways has been illustrated in a number of studies. The main effect of high light intensity is the damage to the chloroplasts and the antennae complex (Davletova et al., 2005; Moller et al., 2007; Triantaphylidès et al., 2008). The maximal efficiency of PSII and the accumulated ROS, share a linear relationship between each other. Thermal damage to photosystems leads to less absorption of photon. In severe thermal stress conditions, the photons absorbed by PSI and PSII are considered as surplus electrons, and serve as the source of ROS (Moller et al., 2007). High atmospheric $\mathrm{CO}_{2}$ levels have been found to stimulate photosynthesis in $\mathrm{C} 3$ plants because of decreased photorespiration, which is widely accepted as a major source of $\mathrm{H}_{2} \mathrm{O}_{2}$ (Miller et al., 2008). Therefore, low $\mathrm{CO}_{2}$ level activates ROS generation leading to the activation of abiotic and biotic stress responses (MunnéBosch et al., 2013). $\mathrm{H}_{2} \mathrm{O}_{2}$ mediates the expression of a number of genes $-\mathrm{H}_{2} \mathrm{O}_{2}$ induced transcripts have been found to play an important role and encoded proteins with functions such as metabolism, cellular energy production, protein destination and transport, cellular organization and biogenesis, cell rescue of defense, and transcription (Desikan et al., 2001; Neill et al., 2002) (Figure 1). Activation of signaling molecules such as $\mathrm{Ca}^{2+}$, salicylic acid (SA), abscisic acid (ABA), jasmonic acid (JA), ethylene, nitric oxide (NO) have been reported to be directly or indirectly linked with $\mathrm{H}_{2} \mathrm{O}_{2}$ signaling and vice versa. More studies have provided evidence that $\mathrm{H}_{2} \mathrm{O}_{2}$ itself is a key signal molecule mediating a series of molecular stress responses, being a part of the signaling cascade (Desikan et al., 2004), and activating many other important signal molecules $\left(\mathrm{Ca}^{2+}, \mathrm{SA}\right.$, ABA, JA, ethylene, NO) of plants (Schieber and Chandel, 2014; Vaahtera et al., 2014). These signal molecules function together 


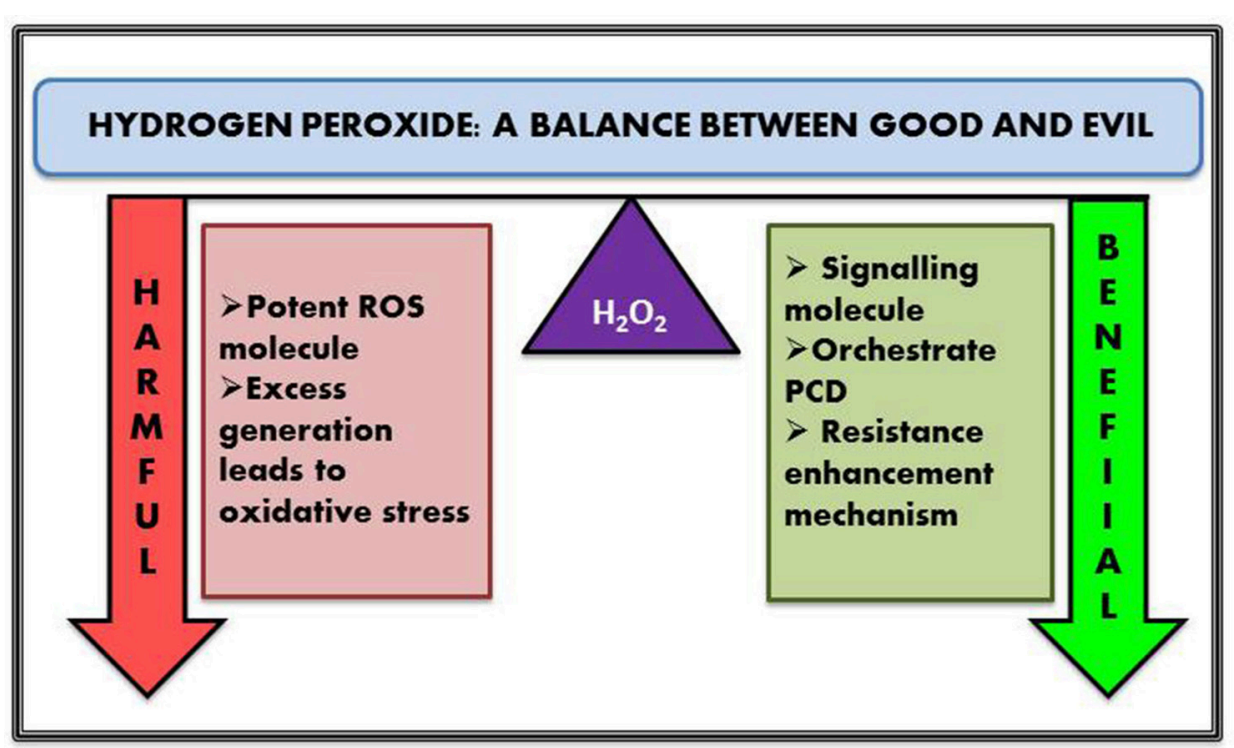

FIGURE 1 | Dual role of intercellular hydrogen peroxides.

and play a complex role in signal transduction of resistance responses, and growth and development in plant. $\mathrm{H}_{2} \mathrm{O}_{2}$ as a signaling molecule has drawn attention in the last decade or so and ample evidence has been found which supports these assumptions (Dat et al., 2000; Baxter et al., 2014; Saha et al., 2015). Apart from its role as master player in plant stress response regulator it was also reported as the most basic key ingredient in regulating several physical and physiological aspects of plant growth and development such as cell cycle, stomatal movement, photosynthesis, photorespiration, and senescence (Bright et al., 2006; Mittler et al., 2011).

Exogenous application of molecules like polyamines has remained an important genre of studying ways to ameliorate stress in plants (Roy et al., 2005; Farooq et al., 2009; Gupta K. et al., 2012; Gupta S. et al., 2012; Sengupta et al., 2016). Abiotic stress causes drastic changes in the pathways involved in the metabolism of $\mathrm{N}_{2}$ and polyamine. The exact role of these polycationic molecules had remained undefined for many years. With the use of model systems like Arabidopsis thaliana, there has been a global approach in deciphering the role of the polyamines and unveiling its metabolic pathway (Ferrando et al., 2004). According to recent studies, the maintenance of proper equilibrium of its catabolic and anabolic pathways along with the modulations of $\mathrm{H}_{2} \mathrm{O}_{2}$ level during these processes indeed help plants to tide over stress and adapt properly to the surrounding environment. Recent studies indicate that the redox gradient across the plasma membrane is a key sensor of global climatic change and a crucial regulator of redox signaling (Munné-Bosch et al., 2013). The impact of this global climate change on agriculture will be enormous and it is essential for our survival to note various aspects of $\mathrm{H}_{2} \mathrm{O}_{2}$ function and crosslinks with regulatory molecules like polyamines.

\section{POLYAMINES-ANABOLISM, CATABOLISM, AND CONJUGATION}

Polyamine biosynthesis in plants progress through the decarboxylation step(s) of ornithine or arginine (Figure 2). In the presence of enzymes, namely either ornithine or arginine decarboxylases (ODC or ADC), the diamine putrescine is formed. The ADC pathway, which yields putrescine, consists of three sequential enzymatic steps, beginning from agmatine iminohydrolase (AIH) and ending at N-carbamoyl putrescine amidohydrolase (CPA). Sequential addition of aminopropyl groups to putrescine and spermidine leads to synthesis of higher molecular weight polyamines by the activity of spermidine synthase and spermine synthase. SAM decarboxylase helps in generating the amino-propyl groups (Figure 2). Analysis and characterization of genes encoding these enzymes in Arabidopsis has shown that in this plant there is only ADC activity and the ODC activity is not detectable (Hanfrey et al., 2001), whereby indicating that putrescine is produced exclusively through the ADC pathway. Moreover, it has been found that in Arabidopsis there are two genes encoding $\mathrm{ADC}(A D C 1$ and $A D C 2)$, a single gene, each for AIH and CPA (Janowitz et al., 2003; Piotrowski et al., 2003) and at least four for SAM decarboxylase (SAMDC1, SAMDC2, SAMDC3, and SAMDC4) (Urano et al., 2004). Also, it has been further observed that there are two genes for spermidine synthase (SPERMIDINES1 and SPERMIDINES2).

Both anabolic and catabolic pathways regulate the levels of polyamine whose intracellular levels depend not only on their biosynthesis but also on catabolic and conjugation reactions. Two main enzymes namely amine oxidases, in particular diamine oxidases (DAO) and polyamine oxidases (PAO), catalyze the deamination of polyamines. DAOs display high affinity for diamines, while PAOs oxidize secondary amine groups 


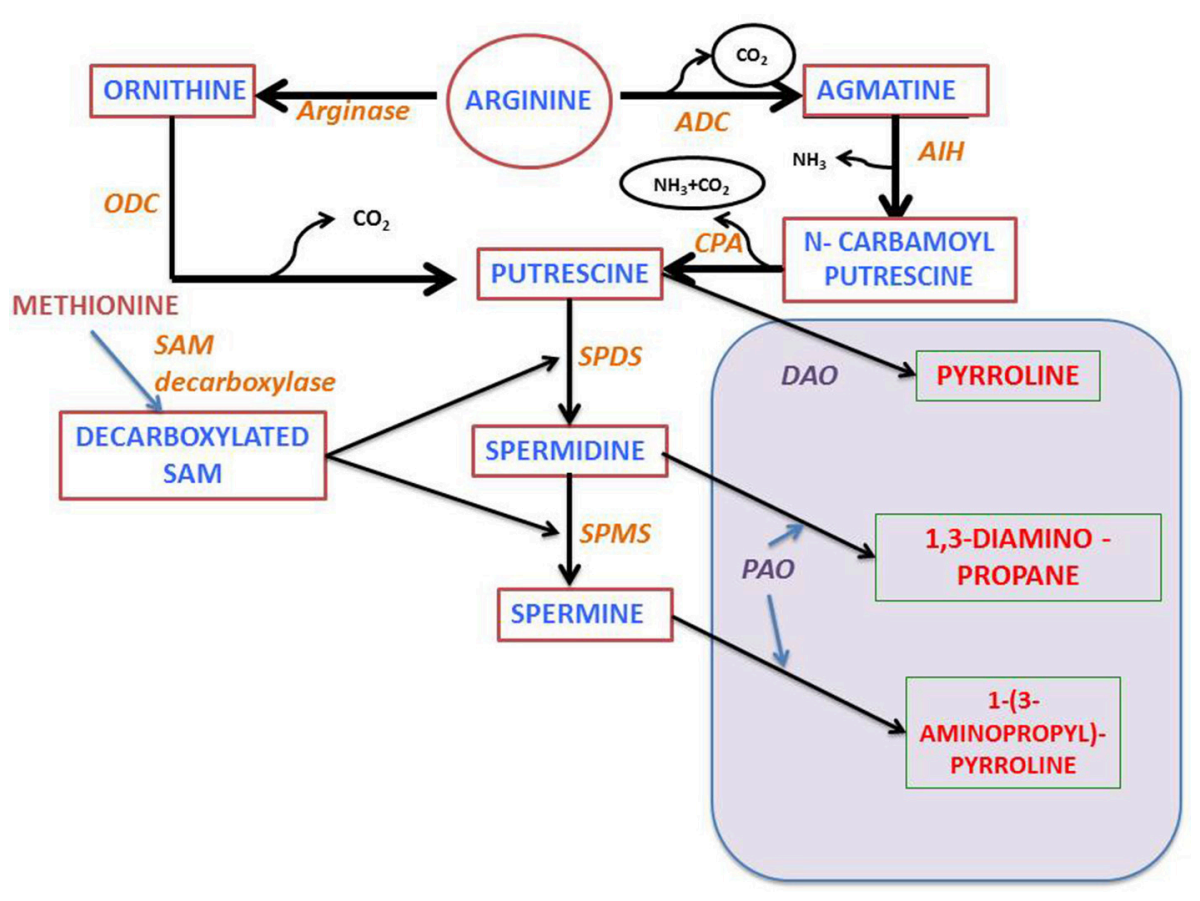

FIGURE 2 | Polyamine metabolism: PA, Polyamine; ODC and ADC, Ornithine or arginine decarboxylase; AlH, agmatine iminohydrolase; CPA, $\mathrm{N}$-carbamoylputrescine amidohydrolase; DAO, diamine oxidase; SPDS, spermidine synthase; SPMS, spermine synthase; SAM, S-adenosylmethionine; PAO, polyamine oxidase (see text for further details).

from spermidine and spermine. The A. thaliana genome contains 12 genes with sequence homology to DAOs from other species, and 5 PAO genes (Moschou et al., 2012). Polyamines not only form base conjugates but also conjugate with other macromolecules like proteins and hydrocinnamic acid (reviewed by Hussain et al., 2011; Gupta et al., 2013a). Enzymes which are involved in the conjugation reactions are transglutaminase and putrescine hydroxycinnamoyl transferase respectively (Bagni and Tassoni, 2001). In Arabidopsis, one gene encoding the enzyme transglutaminase has been characterized (AtPng1) (Della Mea et al., 2004). However, till date putrescine hydroxycinnamoyl transferase encoding gene has not yet been identified. Involvement of secondary metabolites in plant abiotic stress response has been widely studied using $A$. thaliana as a model plant (Ferrando et al., 2004). Arabidopsis whole genome sequencing (Arabidopsis Genome Initiative 2000) enabled researchers to identify all the genes that are involved in polyamine anabolic and catabolic pathways. Genome-wide expression profiling of genes involved in abiotic stress responses provided a global view on plant defense mechanism in light of polyamine metabolism (e.g., using AtGenExpress; Kilian et al., 2007). Apart from genome level analysis, transcriptomic approach is another well-established method used for recognizing the underlying interrelationship among the abiotic stress induced transcripts along with their cis-regulatory elements (Kilian et al., 2007). A similar kind of work was carried out by Ma and Bohnert (2007), where they correlated the presence of specific cis-regulatory motifs with the expression profile of several stress induced genes. They observed that these stress regulatory motifs are profoundly involved in modulating the functions and expression of genes that show differential responses when exposed to abiotic stress. Gong et al. (2016) suggest that SISAMS1 (Sadenosylmethionine synthetase 1) function as a stress mediatory element enhancing alkali stress tolerance through polyamine and $\mathrm{H}_{2} \mathrm{O}_{2}$ cross-linked networks in tomato callus. This provide us with a new insight in plant's alkali stress tolerance mechanism.

Several genes involved in polyamine biosynthetic pathways have so far been already reported to be upregulated when exposed to one or combination of one or more abiotic stresses. Putrescine is the first polyamine that is accumulated in cells on exposure to abiotic stress. Interestingly, increase in putrescine concentration leads to the induction of enzymes that are responsible for the conversion of putrescine to spermidine and spermine, through auto-regulation process. Concentration of putrescine, spermidine, and spermine varies greatly within the cell mostly because of the simultaneous degradation pathway which occurs within the cell, whereby generating $\mathrm{H}_{2} \mathrm{O}_{2}$. This $\mathrm{H}_{2} \mathrm{O}_{2}$, generated as a result of polyamine catabolic pathway, cause oxidative stress on one hand while on the other it plays an essential role in lignification of cell wall, thus protecting plant from adverse effect of stress. Modulating the level of endogenous polyamine by regulating biosynthetic genes is an important procedure for studying the role of polyamine metabolism in stress alleviation (Alcazar et al., 2006). 


\section{$\mathrm{H}_{2} \mathrm{O}_{2}$ PRODUCTION AND CELLULAR DISTRIBUTION-A NECESSARY EVIL}

Generation of ROS is considered as an indispensible outcome of aerobic metabolism, which comes along with its share of goodness and evilness. A plethora of ROS species have been identified in plants including $\mathrm{H}_{2} \mathrm{O}_{2}$, superoxide anion $\left(\mathrm{O}_{2}^{-}\right)$, hydroxyl radicals $(\mathrm{OH})$, singlet oxygen $\left({ }^{1} \mathrm{O}_{2}\right)$, and nitric oxide (NO) and surprisingly most of them are interconvertible. For instance superoxide molecules on reduction yields $\mathrm{H}_{2} \mathrm{O}_{2}$, which on further reduction liberates water and hydroxyl radical. Cellular oxidation reactions involving these molecules have just the reverse sequence. Studies have shown that only $0.1 \%$ of the total oxygen consumed by the plants is diverted for the production of ROS (Bhattacharjee, 2005). ROS is considered as a necessary evil as it functions in several developmental and adaptive responses in both animal and plant cells while its excess generation leads to severe oxidative damage. So it is necessary to maintain a balance between the beneficial and deleterious effects demonstrated by ROS for proper cellular function. Among the different intracellular ROS species, $\mathrm{H}_{2} \mathrm{O}_{2}$ is considered as one of the most prevalent one. In contrast to other ROS mentioned above, it has a relatively long half-life and can be produced in all cell compartments. Moreover, as it is highly diffusible, it can easily pass membranes. The endogenous $\mathrm{H}_{2} \mathrm{O}_{2}$ content of plant cells is usually much higher than that found in animals and bacteria; plant cells happily survive with $\mathrm{H}_{2} \mathrm{O}_{2}$ levels that would kill animal cells. This tolerance is linked to the presence in plant cells of highly efficient antioxidant systems described in detail later on Costa et al. (2010). It is generated by a number of ways in plants. Malfunctioning chloroplast and mitochondrial electron transport chain serves as one of the major source of $\mathrm{H}_{2} \mathrm{O}_{2}$ generation in plant cells. The process is carried out by membrane bound NADPH Oxidases, also known as respiratory burst oxidase homologs (rbohs), which are regulated by a unique class of Rho-like proteins called ROPs (Rhorelated GTPases from plants) as well as by cell wall-associated peroxidases (Agrawal et al., 2003). NADPH Oxidases initially reduce molecular $\mathrm{O}_{2}$ to superoxide molecule with simultaneous oxidation of NADH to FAD. Superoxide molecule thus produced is converted into $\mathrm{H}_{2} \mathrm{O}_{2}$ by the action of another enzyme known as superoxide dismutase. Some form of peroxidases (type III POX), in addition to their role in oxidation of phenolics required for cell wall loosening and stiffening, can generate $\mathrm{H}_{2} \mathrm{O}_{2}$ coupled with the oxidation of NADH (Andronis et al., 2014). In addition, there are several flavin containing limited-substrate oxidases like peroxisomal glycolate oxidase, glyoxisomal xanthine oxidase and urate oxidase, which directly produce $\mathrm{H}_{2} \mathrm{O}_{2}$ (Delrio et al., 1992). A sulfite oxidase localized in the peroxisome has also been identified to have a role in production of $\mathrm{H}_{2} \mathrm{O}_{2}$ (Hänsch et al., 2006). Apart from these, oxidases such as $\mathrm{DAO}$ and PAO, which are involved in the polyamine degradation pathways, also serve as source to the $\mathrm{H}_{2} \mathrm{O}_{2}$ pool. Not only stress but also normal physiological conditions can lead to ROS production as part of various metabolic pathways (Ahmad, 2014). For example, oxygen molecule, which is produced as the byproduct of mitochondrial electron transport chain, is sometimes reduced to superoxides that are in turn dismutated to form $\mathrm{H}_{2} \mathrm{O}_{2}$. Mitochondrial electron transport chain comprises of four distinct enzyme complexes. They are NADH dehydrogenase (Complex I), succinate dehydrogenase (Complex II), ubiquinone-cytochrome $\mathrm{C}$ oxidoreductase (Complex III), and cytochrome oxidase (Complex IV). Electron transfer occurs involving either complex I, III, and IV or complex II, III, and IV, leading to the generation of molecular $\mathrm{O}_{2}$. The molecular $\mathrm{O}_{2}$ generated can be reduced to superoxide and the reduction is catalyzed by ubiquinone of complex III, which serves as one of the major site for ROS-such as superoxide and $\mathrm{H}_{2} \mathrm{O}_{2}$ generation. Complex III bears two ubiquinone binding sites, one is located near the inner surface of the inner mitochondrial membrane while the other one is on the outer surface, which indicates the presence of ROS on both luminal and matrix side of this membrane. Not only the mitochondrial electron transport chain, but the chloroplast electron transport chain also transfers electron from photosystem II to NADP thereby yielding reduced NADPH which is used during the Calvin cycle for reduction of $\mathrm{CO}_{2}$. This also serves as a potent site for superoxide anion and $\mathrm{H}_{2} \mathrm{O}_{2}$ generation. Other subcellular organelles that actively participate in $\mathrm{H}_{2} \mathrm{O}_{2}$ production are peroxisomes and glyoxisomes (present only in plants) which carries out several reactions including beta oxidation of fatty acids and light dependent oxidation of glycolate to glyoxylate by glycolate oxidase (Foyer and Noctor, 2005) (Figure 3). Thus, it is understandable that generation of $\mathrm{H}_{2} \mathrm{O}_{2}$ is an irrevocable process irrespective of its consequences.

$\mathrm{H}_{2} \mathrm{O}_{2}$ plays a versatile role in plants-at mild concentration it acts as a signal molecule and is involved in the alleviation of various abiotic and biotic stresses (Jaspers and Kangasjarvi, 2010; Mittler et al., 2011; Dietz et al., 2016 and its references). At the same time higher cellular concentration of $\mathrm{H}_{2} \mathrm{O}_{2}$ orchestrates unwarranted PCD and leaf senescence in plants (Dat et al., 2000; Gadjev et al., 2008). $\mathrm{H}_{2} \mathrm{O}_{2}$ also takes part in plant cell wall reinforcement (lignification, cross-linking of cell wall structural proteins), phytoalexin production and resistance enhancement against different forms of stresses (Gill and Tuteja, 2010; Ahmad, 2014). In case of biotic stress, $\mathrm{H}_{2} \mathrm{O}_{2}$ production in plants might trigger killing of the pathogen either directly or by prompting defense genes to limit infection by the microbe. Hypersensitive responses are the master players behind establishment of plant immunity against disease causing pathogens. It is another well-known approach that leads to PCD in plant thus inhibiting pathogen invasion. $\mathrm{H}_{2} \mathrm{O}_{2}$ is the key signaling molecule that actively participates in mediating hypersensitive responses by triggering localized host cell death. It has been also reported to play a crucial role in regulating hormone mediated signaling and vice versa (Pei et al., 2000). A classic example of hormone-mediated response is stomatal closure, where presence of $\mathrm{H}_{2} \mathrm{O}_{2}$ is perceived by histidine kinase receptor ETR1, which further transduces the signal and ensures the closing of stomata (Bright et al., 2006). Efficiency of any signaling molecule lies in the fact that they are rapidly produced and removed immediately once it has accomplished its role, and $\mathrm{H}_{2} \mathrm{O}_{2}$ fits the bill perfectly. They are produced rapidly by various cellular processes and quenched promptly. In addition, 


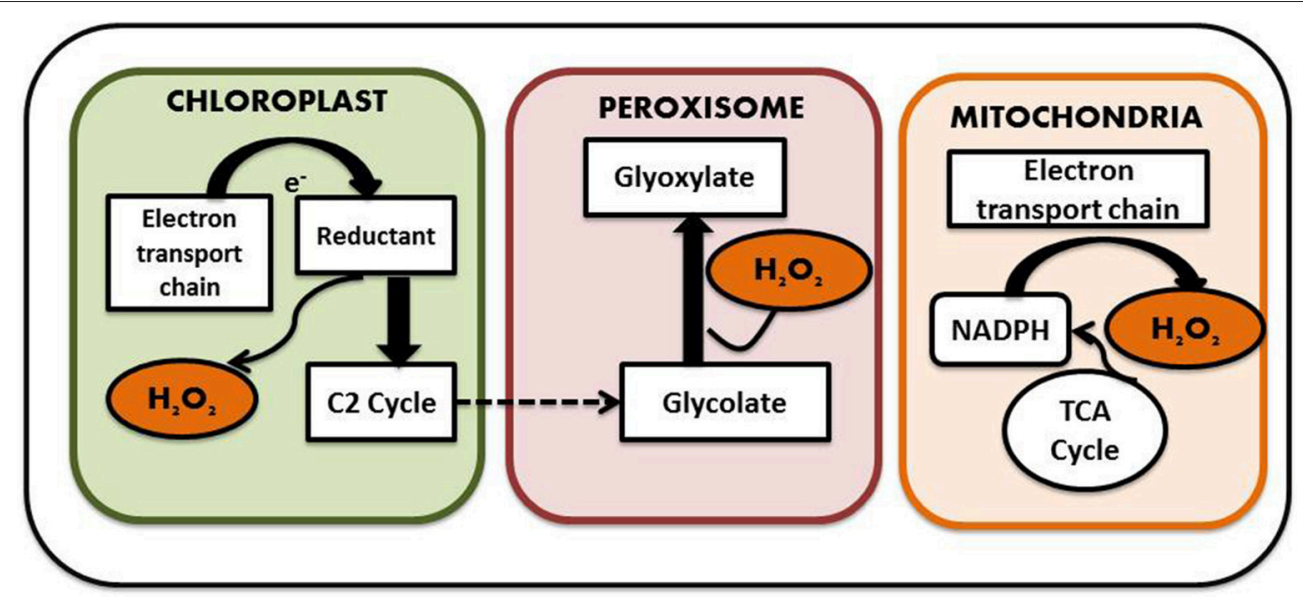

FIGURE 3 | Subcellular localization of $\mathrm{H}_{2} \mathrm{O}_{2}$ (see text for details).

it can easily react with different biomolecules such as membrane lipid, carbohydrate, protein and DNA and can effortlessly diffuse through aquaporins, thus generating further molecular responses. Apart from its role in hypersensitive reaction and PCD, $\mathrm{H}_{2} \mathrm{O}_{2}$ induces the expression of glutathione-S-transferase and glutathione peroxidase encoding genes. $\mathrm{H}_{2} \mathrm{O}_{2}$ treated $E$. coli cells exhibited 140 upregulated mRNA transcripts in DNA microarray experiments-thus revealing the role of $\mathrm{H}_{2} \mathrm{O}_{2}$ in signal transduction (Li et al., 2001). A similar kind of study was carried out by Desikan et al. (2001) in arabidopsis where about 175 non-redundant EST's were reported those of which are modulated by $\mathrm{H}_{2} \mathrm{O}_{2}$. Generally signaling molecule activates its receptor by complimentary binding-however, in case of $\mathrm{H}_{2} \mathrm{O}_{2}$, signal transduction occurs via chemical reactions. Oxidation of cysteine residue of a receptor protein is considered as one of the major path for mediating intracellular signals (Paulsen and Carroll, 2010). There are also evidences that suggest their interaction with secondary messengers such as MAP kinase and their activation. These activated MAP kinase molecules in turn activate different transcription factors thus initiating intricate signaling cascades (Asai et al., 2000). It is interesting to note that $\mathrm{H}_{2} \mathrm{O}_{2}$ generated from different cellular organelles unveil a plethora of molecular responses. For example $\mathrm{H}_{2} \mathrm{O}_{2}$ produced from chloroplast was observed to be involved in early signaling responses such as activation of transcription factors and secondary messenger biosynthetic genes while $\mathrm{H}_{2} \mathrm{O}_{2}$ generated from peroxisomes are mostly involved in upregulating the genes involved in protein repair pathway (Sewelam et al., 2014).

$\mathrm{H}_{2} \mathrm{O}_{2}$ seems to share a unique inter-relationship with $\mathrm{NO}$ and $\mathrm{Ca}^{2+} \cdot \mathrm{H}_{2} \mathrm{O}_{2}$ and NO together have been reported to play an essential role in plant developmental and physiological processes such as growth of pollen tube, growth and development of root, closing of stomata, delayed senescence etc. (Serrano et al., 2012; Huang et al., 2015; Iakimova and Woltering, 2015; Shi et al., 2015). Not only developmental processes, they together play an active role in abiotic stress alleviation as well. They protect drought stressed leaf mesophyll tissue from damage and also increase the activity of myo-inositol phosphate synthase in drought stressed plants (Liao et al., 2010). They have been reported to increase low temperature tolerance by mediating polyamine oxidation in Medicago (Guo et al., 2014). There are several other evidences that confirm the role of both $\mathrm{H}_{2} \mathrm{O}_{2}$ and $\mathrm{NO}$ in remitting abiotic stress. However, the mechanism behind their interaction is still not very clear. Most probably $\mathrm{H}_{2} \mathrm{O}_{2}$ functions as a cofactor in endogenous $\mathrm{NO}$ synthesis. This view has been endorsed by the findings of Lin et al. (2012) and Shi et al. (2015). NO on the other hand can regulate stomatal closure in $\mathrm{H}_{2} \mathrm{O}_{2}$ mutant and in wild type plant treated with $\mathrm{H}_{2} \mathrm{O}_{2}$ scavengers and inhibitors. Thus, it can be clearly said that both of their production pathways are inter-related and can regulate production of each other. Other than with $\mathrm{NO}, \mathrm{H}_{2} \mathrm{O}_{2}$ has been found to share a distinctive bond with $\mathrm{Ca}^{+2}$ as well. Endogenous $\mathrm{Ca}^{2+}$ influx increase in arabidopsis root epidermis on application of exogenous $\mathrm{H}_{2} \mathrm{O}_{2}$. This increase in $\mathrm{Ca}^{2+}$ influxes in the root plasma membrane of arabidopsis seedling leads to root elongation. $\mathrm{Ca}^{2+}$ influx is probably mediated by $\mathrm{H}_{2} \mathrm{O}_{2}$ dependent activation of Anexin 1 protein, which is a $\mathrm{Ca}^{2+}$ transport protein, thus promoting its growth and development (Demidchik et al., 2007; Richards et al., 2014; Han et al., 2015). Another striking example that demonstrates the inter-relationship between $\mathrm{H}_{2} \mathrm{O}_{2}$ and $\mathrm{Ca}^{2+}$ is $\mathrm{H}_{2} \mathrm{O}_{2}$ dependent adventitious root formation, which involves $\mathrm{Ca}^{2+}$ signaling. In fact the removal of intracellular $\mathrm{Ca}^{2+}$ prevents formation of adventitious root. Pei et al. (2000) established a clear association between $\mathrm{H}_{2} \mathrm{O}_{2}, \mathrm{Ca}^{2+}$ and stomatal closure using patch clamp techniques, thus connecting $\mathrm{ABA}$ signaling cascades with stomatal closure mediated by $\mathrm{H}_{2} \mathrm{O}_{2}$ and $\mathrm{Ca}^{2+}$ channels. Thus, all available evidences point toward an intricate crosstalk between $\mathrm{H}_{2} \mathrm{O}_{2}$ and $\mathrm{Ca}^{2+}$.

So considering all the roles played by $\mathrm{H}_{2} \mathrm{O}_{2}$-either good or bad-be it as stress alleviator, secondary messenger, chemoselective signaling molecule or stress inducer, it surely deserves the tag "Jack of many trades." 


\section{SCAVENGERS EMPLOYED TO LIMIT THE OXIDATIVE DAMAGE}

Generation of ROS and aerobic life goes hand in hand, and these two phenomena are inseparable. So to deal with the situation-living organisms have evolved several ROS scavenging mechanisms-such as administration of enzymatic and nonenzymatic antioxidants that confer protection against oxidative stress. Among the various ROS species that are present within a cell, $\mathrm{H}_{2} \mathrm{O}_{2}$ is most stable with a half-life of $1 \mathrm{~ms}$ while the half-life of others are much shorter, i.e., about 2-4 $\mu \mathrm{s}$ (Bhattacharjee, 2005). In general $\mathrm{H}_{2} \mathrm{O}_{2}$ is considered as a weak oxidizing agent. A number of investigations have revealed that ROS, especially $\mathrm{H}_{2} \mathrm{O}_{2}$, plays an important role related to the signal transduction involved in plant adaptation to the changing environment (Pei et al., 2000; Neill et al., 2002; Moon et al., 2003; Terzi et al., 2014; Reczek and Chandel, 2015). Although the presence of $\mathrm{H}_{2} \mathrm{O}_{2}$ sensor protein still remain unelucidated, it is presumed that $\mathrm{H}_{2} \mathrm{O}_{2}$ is directly perceived by the redox transcription factors, showing redox sensitivity, which in turn activates the downstream signaling cascades. It also participates in several physiological pathways of plant and activates defense responses to various stresses. $\mathrm{H}_{2} \mathrm{O}_{2}$ is beginning to be accepted as a second messenger due to some features that are exclusively present in all secondary messenger molecules. It is mobile, small and can diffuse in and out of the cell freely thereby relaying signals between different cellular compartments, thus modulating different biological processes (Neill et al., 2002). However, excess accumulation of $\mathrm{H}_{2} \mathrm{O}_{2}$ adversely affects the plants by leading to oxidative stress. Therefore, presence of efficient $\mathrm{H}_{2} \mathrm{O}_{2}$-scavenging mechanisms is a compulsory criterion for all aerobic organisms. Antioxidative enzymes, and certain non-enzymatic antioxidants (Miller et al., 2008; Sung et al., 2011; Saha et al., 2015) work in tandem and maintain a sinuous but delicate balance to detoxify $\mathrm{H}_{2} \mathrm{O}_{2}$. Among the wide array of antioxidative enzymes that function in scavenging ROS species, Catalase (CAT), Ascorbate peroxidase (APX), and Peroxidases (POX) require special mention as they act directly upon the $\mathrm{H}_{2} \mathrm{O}_{2}$ molecules, thus reducing it to water. SOD carries out the dismutation reaction by reducing $\mathrm{O}_{2}^{-}$molecule to $\mathrm{H}_{2} \mathrm{O}_{2}$ whereas CAT, APX, GPX are involved in converting $\mathrm{H}_{2} \mathrm{O}_{2}$ to water thus ensuring its removal. Based on the presence of metal ion, SOD can be classified into three different types(i) Mn-SOD, which is located in the mitochondrial matrix and peroxisome, (ii) $\mathrm{Cu} / \mathrm{Zn}-\mathrm{SOD}$, which is present in large quantities in the chloroplast and cytosol, and (iii) Fe-SOD, which is localized only in chloroplastids of higher plants. All of them function together when the plant is exposed to unfavorable conditions thus protecting the cells from probable damage. $\mathrm{H}_{2} \mathrm{O}_{2}$ which is generated as a result of superoxide dismutation is removed by enzymes such as CAT, five different isoforms of APX and different isozymes of GPX. These biological catalysts are localized in all the organelles where $\mathrm{H}_{2} \mathrm{O}_{2}$ generating enzymes are present such as peroxisome, glyoxisome, cytosol, mitochondria etc. CAT is the major enzyme involved in the quenching of $\mathrm{H}_{2} \mathrm{O}_{2}$ with highest enzyme turnover rate. Studies have revealed that about six million $\mathrm{H}_{2} \mathrm{O}_{2}$ molecules can be converted to $\mathrm{H}_{2} \mathrm{O}$ and $\mathrm{O}_{2}$ per minute by one molecule of CAT, thereby making CAT one of the major enzymes involved in $\mathrm{H}_{2} \mathrm{O}_{2}$ detoxification. Apart from CAT another enzyme that plays an equally important role is APX, which catalyses the first step in AsA-GSH cycle and works in coordination with ascorbic acid and glutathione (Asada, 2006; Fan and Huang, 2012; BegaraMorales et al., 2013; Jahan and Anis, 2014). Apart from the enzymatic antioxidants some non-enzymatic antioxidants such as $\alpha$-tocopherol, ascorbic acid (AsA), glutathione etc. also play a vital role in sustaining stable redox state by removing excess ROS from different cellular compartment, thus detoxifying the cell. AsA that is synthesized in mitochondria, is uniformly distributed throughout the plant and serve as a substrate for APX enzyme, which reduces $\mathrm{H}_{2} \mathrm{O}_{2}$ to water, yielding mono-dehydroascorbate (MDA) in ascorbate-glutathione cycle (AsA-GSH cycle) (Gapper and Dolan, 2006). It helps regulating $\alpha$-tocopherol level in cells and is also involved in biosynthesis of zeaxanthine pigment which protects the plant from photo-oxidation or photo-bleaching (Foyer and Noctor, 2005; Munné-Bosch, 2007), thus pursuing an important role in oxidative stress tolerance. Several studies have revealed that application of exogenous AsA diminishes the harmful effect of oxidative stress (Hossain et al., 2011). Glutathione, another non-protein thiol, and a non-enzymatic antioxidant, also plays an essential role in $\mathrm{H}_{2} \mathrm{O}_{2}$ scavenging (comprehensive review by Noctor et al., 2012). Conversion of reduced glutathione (GSH) to oxidized glutathione (GSSG) and its ratio is considered as a marker for determining redox balance within the cell. Functionally it is almost similar to AsA but in addition to that it also plays an eminent role in heavy metal chelating. Therefore, both glutathione and ascorbic acid are now contemplated as the chief ingredients of redox signaling. Moreover, another group of biomolecules that should be mentioned in this context are polyamines. As mentioned earlier, polyamines are positively charged molecules which protect the cell from oxidative damage both directly and indirectly. Directly it functions as an antioxidant itself thus scavenging free radicals and indirectly it has been reported to regulate the level of enzymatic and non-enzymatic antioxidants within the cell (Groppa and Benavides, 2008). Thus, increase in polyamine concentration is often correlated with increase in stress tolerance. However, on the other hand polyamine catabolism is one of the major contributors of $\mathrm{H}_{2} \mathrm{O}_{2}$ to the $\mathrm{H}_{2} \mathrm{O}_{2}$ pool. Endogenous polyamines, like $\mathrm{H}_{2} \mathrm{O}_{2}$, play a dual role by both adding and diminishing the concentration of $\mathrm{H}_{2} \mathrm{O}_{2}$ within the cell, thereby maintaining a thin line of balance between their molecular concentrations. Since the maintenance of appropriate $\mathrm{H}_{2} \mathrm{O}_{2}$ concentration within the cell is of utmost importance for carrying out normal physiological and developmental processes and to combat abiotic stress in plants, efficient ROS scavenging mechanism along with adequate polyamine concentration is of vital importance for its sustainable growth and survival.

\section{ROLE OF POLYAMINE IN OXIDATIVE STRESS}

Plant stress biologists have marked oxidative stress as an after effect of each and every abiotic stress-be it heavy metal accumulation, excess salinity, high and low temperature or 
scarcity of water. Each of these abiotic stresses is associated with the generation of excess ROS, leading to oxidative damage to cellular components. Studies have revealed that application of exogenous polyamines alleviate abiotic stress, thereby conferring stress tolerance. Abiotic stress is known to impair cellular membranes through their interaction with the membrane structure or as a result of ROS-mediated peroxidation of membrane lipids (Anjum et al., 2015). The antioxidative effect of polyamines can be attributed to a combination of their anionic and cationic-binding properties in radical scavenging, inhibiting properties of lipid peroxidation, metal-catalyzed oxidative reaction, and production of $\mathrm{H}_{2} \mathrm{O}_{2}$ by DAO and PAO (Groppa and Benavides, 2008). Free and bound polyamines are reported to be modulated by UV-B radiation in different plant species (Mapelli et al., 2008) thereby protecting them against ozone damage and ozone-derived oxidative damage (Groppa and Benavides, 2008). $\mathrm{H}_{2} \mathrm{O}_{2}$ produced by polyamine catabolism may cause activation of antioxidative defense responses. Phenylpropanoidpolyamine conjugates are known to act as antioxidants against ROS and reactive nitrogen species in response to stress conditions (Yamasaki and Cohen, 2006). Shen et al. (2000) reported that spermidine may act as a cellular membrane protectant against chill-induced lipid peroxidation in cucumber through prevention of activation of superoxide-generating NADPH oxidase. As discussed in the earlier section, CAT enzyme plays an essential role in regulating the balance between excess and exact amount of cellular $\mathrm{H}_{2} \mathrm{O}_{2}$. Moreover, polyamines directly or indirectly modulate the level of CAT enzyme when exposed to abiotic stress (Figure 4), thus forming an intricate stress tolerance network. Sung et al. (2011) have demonstrated the role of polyamines in mitigating hypersalinity-induced oxidative stress in a marine green macroalgae (Ulva fasciata) by modulation of antioxidative enzyme (FeSOD, MnSOD, CAT, APX) gene expressions. Radhakrishnan and Lee (2013) observed that, in comparison to untreated plants, CAT activity decreases in polyethylene glycol (PEG) treated soya bean plants simulating drought environment. However, the enzyme activity transiently increases when the plants are treated with PEG along with polyamine spermine. A similar kind of experiment was carried out by Farooq et al. (2009), using rice plant as the experimental model. It was observed that exogenous treatment with spermine successfully ameliorated the effect of osmotic stress by accelerating the activity of CAT enzyme. In another study, acid rain fed bean plants showed a sudden burst in the $\mathrm{H}_{2} \mathrm{O}_{2}$ level which in turn decreased the CAT activity in the cell. This decrease in the CAT activity is probably due to the binding of $\mathrm{H}_{2} \mathrm{O}_{2}$ molecule to the enzyme active site, thus deactivating the enzyme (Sharma et al., 2012; Mittova et al., 2015). However, with longer exposure to acid rain, activity of CAT was found to increase, hence conferring stress tolerance. However, in bean plants pretreated with polyamines (spermine or spermidine), the rapid generation of $\mathrm{H}_{2} \mathrm{O}_{2}$ was checked. This may be due to the protective shield imparted by the polyamines on the membrane which stabilize it (Velikova et al., 2000). Verma and Mishra (2005) demonstrated that under conditions of high salt concentration Brassica plants show an increased level of $\mathrm{H}_{2} \mathrm{O}_{2}$ in plants untreated with polyamines, whereas in polyamine treated plants the level of $\mathrm{H}_{2} \mathrm{O}_{2}$ decreases considerably. It was also observed that CAT activity increases when exposed simultaneously to $\mathrm{NaCl}$ and polyamine, rather than when exposed to $\mathrm{NaCl}$ alone, thereby establishing the role of polyamines in protecting the plants from oxidative injury (Verma and Mishra, 2005). Exogenous application of polyamines reduced the $\mathrm{H}_{2} \mathrm{O}_{2}$ and malondialdehyde (MDA) content, and increased the antioxidant levels in drought and cold stressed 15-day-old chickpea plants (Nayyar and Chander, 2004). DNA oxidative degradation by $\mathrm{OH}^{-}$was inhibited in the presence of spermine in Mesembryanthemum crystallinum (Kuznetsov and Shevyakova, 2007) illustrating the efficiency of polyamines as free radical scavengers. According to some research groups, polyamine conjugates show more efficient antioxidant activities compared to their parent compounds (Edreva et al., 2007; Hussain et al., 2011).

Under metal stress CAT shows a differential response. In some plants like Glycine max, A. thaliana, and Capsicum annuum CAT activity decreases, while in Brassica juncea, Oryza sativa, and Triticum aestivum its activity increases. Another very interesting observation was reported by Hsu and Kao (2007) where it was shown that pretreating a plant with $\mathrm{H}_{2} \mathrm{O}_{2}$ increases the CAT activity which in turn protects the plant from cadmium induced oxidative damage. A similar kind of trend was observed in salt treated Cicer arietinum. A completely opposite trend was noticed by Sharma and Dubey (2007) in drought treated rice seedling, where CAT activity decreases. This observation was congruent with the observation made by Pan et al. (2003) where CAT activity decreases in Glycyrrhiza uralensis seedlings when exposed to both salinity and drought stress. From the above observations it may be concluded that the increase or decrease in CAT activity primarily depends on the nature of sensitivity toward stress of a particular plant. In sensitive variety CAT level tends to increase. On the contrary, in stress tolerant variety the level of CAT activity decreases. Several reports demonstrate that polyamine plays an interesting role in modulating the CAT level thus regulating the $\mathrm{H}_{2} \mathrm{O}_{2}$ content of the cell. So it is easy to hypothesize an inter-relation between endogenous and exogenous polyamines, CAT enzymes and stress generated $\mathrm{H}_{2} \mathrm{O}_{2}$. Most probably, they function in a loop. Oxidative stress leads to generation of $\mathrm{H}_{2} \mathrm{O}_{2}$ which signals activation of CAT enzyme and endogenous polyamine-CAT functions in removal of $\mathrm{H}_{2} \mathrm{O}_{2}$ molecule and polyamines protect the membrane from oxidative damage thus conferring a protective shield. Application of exogenous polyamines strengthen the ROS removal procedure in varieties where CAT activity decreases in response to stress thus forming a perfect interrelated network of tolerance (Figure 5). Polyamines have been instrumental in reducing protein carbonylation and tyrosine nitration while subsequently increasing protein S-nitrosylation.

Previous results have shown that plants employ polyamine catabolism derived $\mathrm{H}_{2} \mathrm{O}_{2}$ as a defensive contrivance against abiotic stress (Cona et al., 2006). Tanou et al. (2014) have reported increase in intracellular DAO and $P A O$ activity in plants treated with excess salt (Figure 6A). Treatment with $\mathrm{NaCl}$ alone have shown to increase both $\mathrm{O}^{\bullet-}$ and $\mathrm{H}_{2} \mathrm{O}_{2}$ production, indicating existence of an oxidative stress situation. It was inferred that in the presence of salt, endogenous 


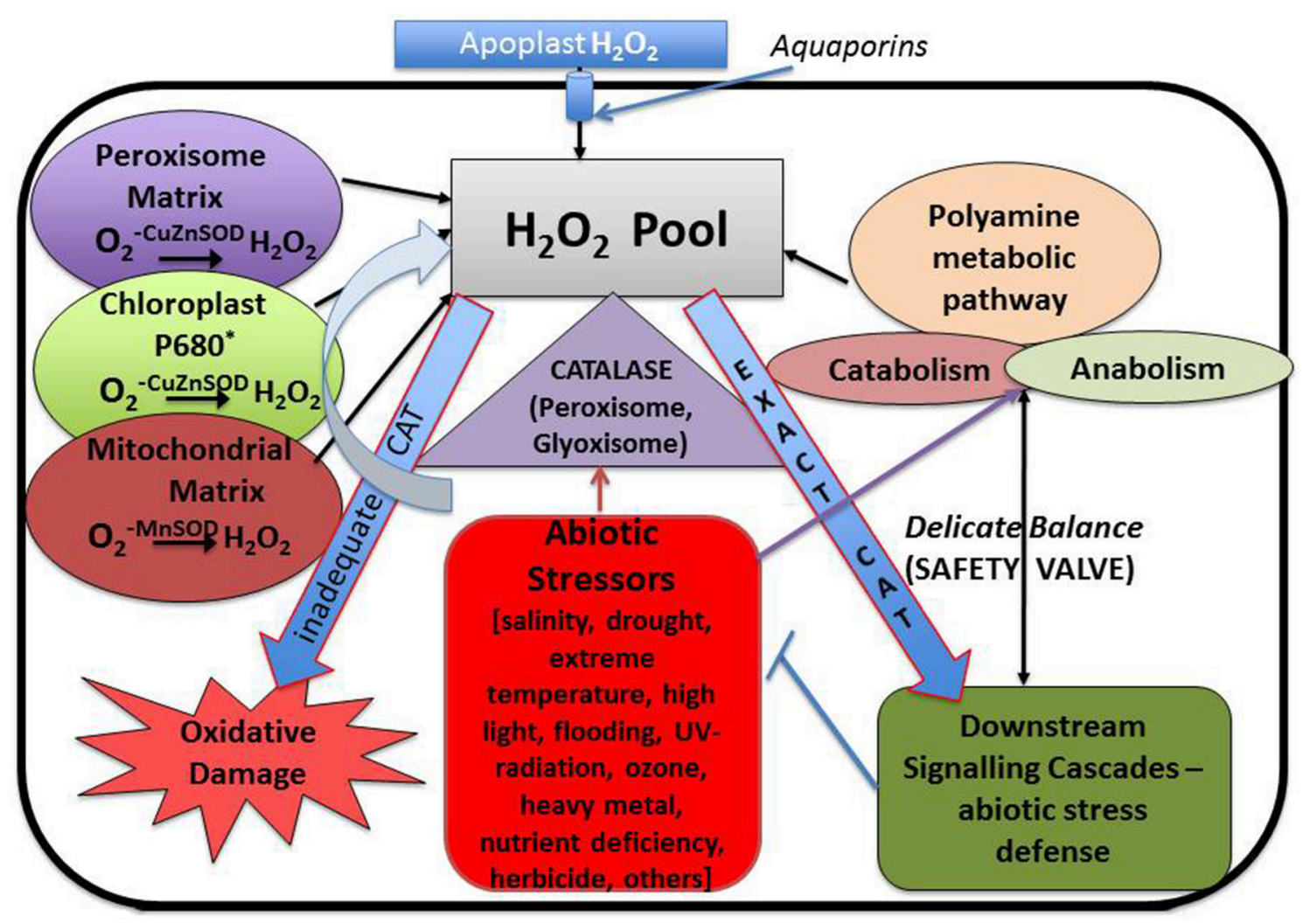

FIGURE 4 | Interrelationship between cellular hydrogen peroxide, polyamine metabolic pathway and different forms of abiotic stresses with special emphasis on the role played by "catalase" antioxidant enzyme.

polyamines induce the generation of $\mathrm{O} 2^{\bullet-}$. However, exogenous polyamine treatment lowers $\mathrm{O}^{\bullet-}$ level, with significant difference being observed after spermine application. In addition, $\mathrm{H}_{2} \mathrm{O}_{2}$ content strongly increases in putrescine or spermidinetreated plants compared to those treated with salt alone. Exogenous polyamine application on salt treated plants shows an increase in endogenous polyamine level when compared to plants which are not treated with polyamines, thereby confirming the beneficial role of extracellular polyamine in mitigating salt stress (Shi et al., 2010). Polyamines have been reported to be taking part in inter-organ signals in plants. Moreover, it was observed that putrescine administration evoke spermidine accumulation in roots on exposure to salinity, whereas spermidine treatment enhances spermine production in leaves, illustrating the metabolic conversions of polyamines in the case of the entire plant. Likewise, the addition of spermine increases the endogenous spermidine and putrescine concentration in roots whereas spermidine application increases leaf putrescine concentration in salt treated citrus, thus depicting the possible conversions that might occur on exposure to a single polyamine under abiotic stress conditions (Tavladoraki et al., 2006; Moschou et al., 2008a,b). Studies have divulged that exogenous application of polyamines in salt treated roots stimulates polyamine biosynthetic genes in the leaves, asserting its universal systematic role (Kuznetsov et al., 2002). Further evidences came from the work of Tassoni et al. (2008), who demonstrated the advantageous effect of free spermidine on Arabidopsis flower under high salt concentration. Another extremely interesting phenomenon observed in Vitis vinifera revealed that stress exposure causes an immediate rise in the putrescine level; however, increase in spermine/spermidine level occur much later (Liu et al., 2011). Photochemical efficiency of PSII which is often hampered by stress was found to be enhanced by external application of putrescine (Zhang et al., 2009). Rice plants treated with spermidine for the first 7 days after germination followed by their continuous exposure to salinity till maturity shows a better grain yield and increased ion content in comparison to those that are not treated with spermidine for the initial 7 days (Saleethong et al., 2013). Thus, it is evident that ROS scavenging mechanisms in co-ordination with polyamines play important role during plant abiotic stress adaptation.

\section{$\mathrm{H}_{2} \mathrm{O}_{2}$ AND POLYAMINES-THE DUAL ROLE}

The actual cause of cell death induced in plants by oxidative stress still remains a conundrum. What remains a pertinent question is-whether PCD is induced by the ROS or is it the ROS levels itself which causes the cells to decease. Polyamine-derived $\mathrm{H}_{2} \mathrm{O}_{2}$ 


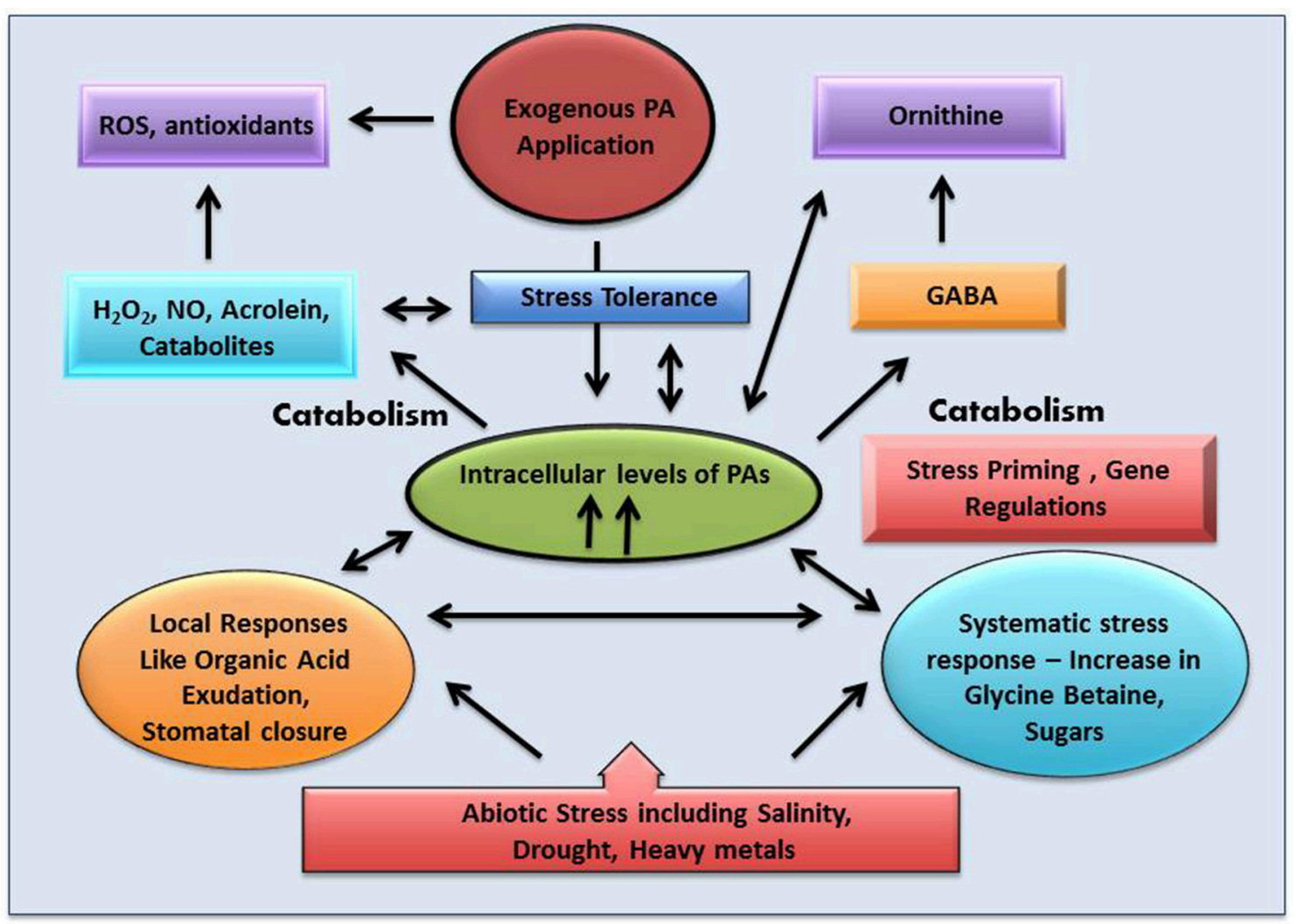

FIGURE 5 | An overview of the role of polyamine (PA) in plant abiotic stress tolerance.

has been shown to participate in stress-induced cell wall stiffening and maturation (Angelini et al., 2010). In HIV-induced neuronal toxicity, Spm oxidase has been shown to act as a mediator of ROS production (Capone et al., 2013). Involvement of $\mathrm{H}_{2} \mathrm{O}_{2}$ in polyamine-induced cell death has been demonstrated in tobacco (Nicotiana tabacum) (Iannone et al., 2013) (Figure 6A). It is in this context that the level of $\mathrm{H}_{2} \mathrm{O}_{2}$ has drawn keen interest by raising doubts in the minds of researchers as to the way in which it leads to cellular damage inducing PCD, and the very fact that it may require a higher level of ROS to exterminate cells by direct oxidation. Studies applying oxidative stress to mutants deficient in different PCD pathways will be able to throw some light on this very question.

Many questions related to ROS metabolism have remained unanswered till date. We are thus trying to address these questions by considering the agency of molecules like $\mathrm{H}_{2} \mathrm{O}_{2}$ and polyamines both of which work toward a common target of stress tolerance. Intra-cellular levels of polyamines play a pivotal role by regulating a large number of processes through its metabolic pathways, including both anabolism and catabolism. Polyamine catabolism leads to an increase in level of $\mathrm{H}_{2} \mathrm{O}_{2}$, in turn influencing both stress damage and the response to stress damage (Pottosin and Shabala, 2014). Other by-products of the catabolic pathways include NO, GABA, acroliens, and others. GABA through TCA along with ornithine and other amino acids also acts as a signaling molecule. Studies demonstrate that external polyamine application not only alters polyamine homeostasis and metabolism systemically, but also affects the levels and the activity of antioxidative enzymes. Polyamines have been reported to be involved in the easing of oxidative stress through stimulation of two transcription factors SoxR and EmrR in E. coli. SoxR supposedly induces a superoxide response regulon transcription activator and $\operatorname{sod} A$ genes. These in turn influence the antioxidant machinery of the bacterial cells. Activation of EmrR and GshA together induces glutathione that has an inhibitory effect on $\mathrm{H}_{2} \mathrm{O}_{2}$ accumulation (Sakamoto et al., 2015) (Figure 6B). Scientists around the world look for such overlapping cues in plants, which help them to design their experiments and hypothesis.

A comprehensive analysis including biochemical, physiological, and molecular assays using microarrays and chips, coupled with proteomics will help us in deciphering the exact pathways both polyamines and $\mathrm{H}_{2} \mathrm{O}_{2}$ work on. Tanou et al. $(2012,2014)$ reported that a plant's response to salinity involves a crosstalk between polyamine transduction and oxidative/nitrosative signaling. Bruce et al. (2007) in their work have efficiently highlighted the benefits of long-term adaptation to biotic and abiotic stresses in plants and their evolutionary significance. They hypothesized that the plant retaliation toward any particular stress is regulated by a combination of their innate ability to combat stress as well as from previous exposure to a similar kind of stress. It was also opined that treating a plant 

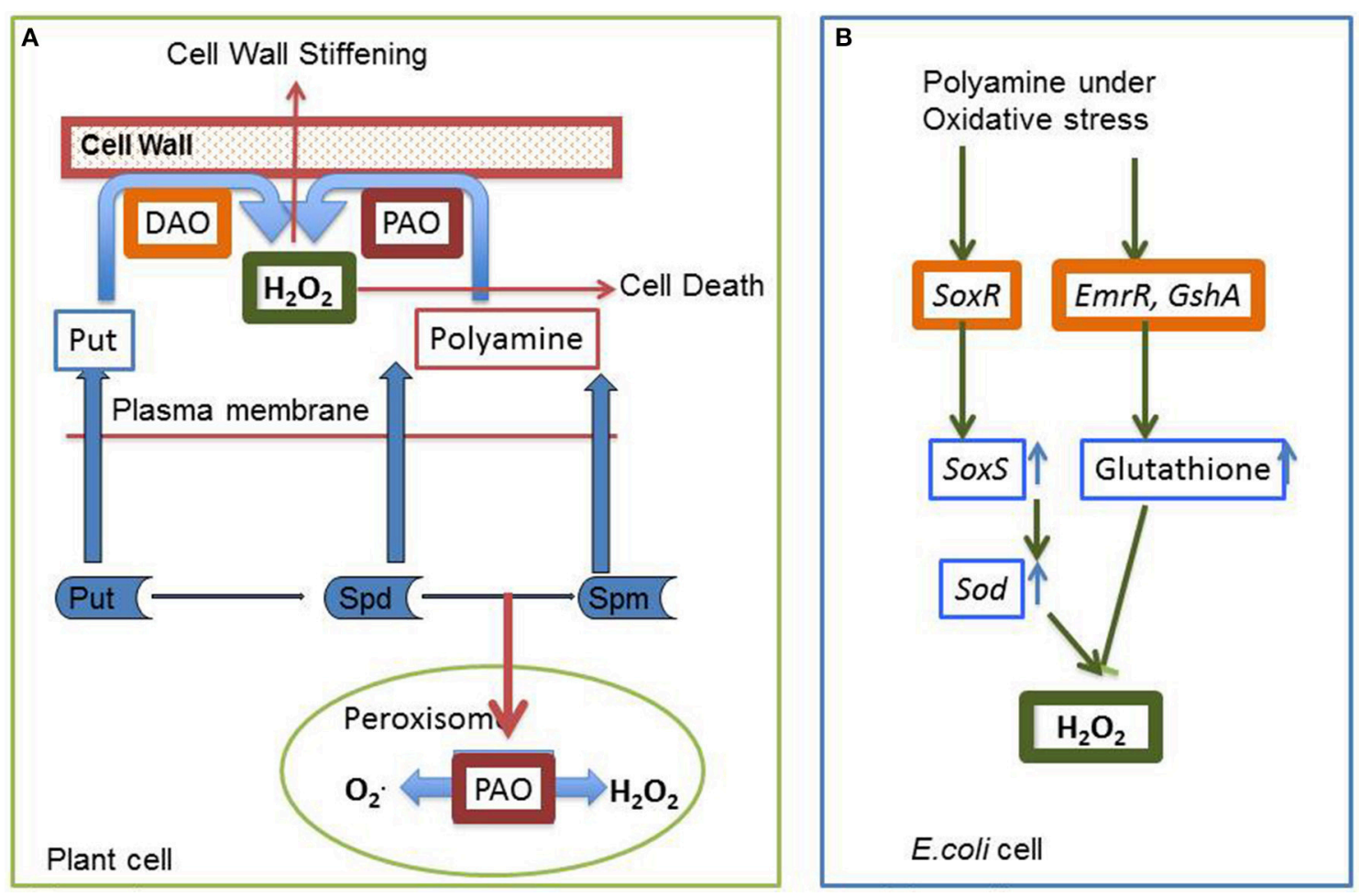

FIGURE 6 | Interaction of polyamine and $\mathrm{H}_{2} \mathrm{O}_{2}$ (A) In plant cells $\mathrm{H}_{2} \mathrm{O}_{2}$ is generated during the process of polyamine catabolism, that may be utilized as a signaling molecule, $\mathbf{P C D}$ or cell wall stiffening. $\mathrm{PAO}$ in peroxisome maintains a delicate balance between $\mathrm{O}_{2}$. and $\mathrm{H}_{2} \mathrm{O}_{2}$ (B) In simple prokaryotic bacterial cell like in $E$. coli, polyamines have been reported to be involved in ameliorating oxidative stress through stimulation of two transcription factors SoxR and EmrR (see text for details).

with any kind of stress alleviator such as polyamines and in some cases even stress inducers such as $\mathrm{H}_{2} \mathrm{O}_{2}$ prior to the exposure to stress increases its chances of resistance and perennate (Shi et al., 2010). Li et al. (2015) analyzed the involvement of polyamines in the regulation of $\mathrm{H}_{2} \mathrm{O}_{2}$ and $\mathrm{Ca}^{2+}$ messenger systems associated with antioxidant defense and dehydrins in leaves of white clover resulting in water stress tolerance. However, further investigations are needed for establishing the phenomenon of polyamine-induced stress tolerance associated with $\mathrm{H}_{2} \mathrm{O}_{2}$ and $\mathrm{Ca}^{2+}$ signaling in different plant species and stress conditions.

The exposure to stress during very early development in plants is known as "priming." There are reported examples of the effects of "priming" on physiological and biochemical responses that plants show on recurrent exposure to assortment variety of stresses (Jisha et al., 2013; Jisha and Puthur, 2016). Priming usually begins during seed germination, and might have longlasting effects on the development of plants. This in fact may lead to adaptation to a diverse type of abiotic and biotic stresses. One can well imagine that it is priming that deals with the epigenetic changes, or markers, which indeed are responsible for carrying information over generations. Modifications of epigenetic regulations due to the changing environment on gene expression are extensively believed to be true; however, the appliance of such epigenetic adaptations is not well understood. The modifications generally occur at the chromatin level, and involve sequence-specific DNA methylation, histone acetylation, sumoylation and other similar abatements. While most of the epigenetic modifications are unwavering within the life of an organism, others are reversible, depending on growth and other regulations, and the rest appear to be transmitted to the subsequent generations through sexual reproduction (Sano, 2010; Shao et al., 2014; Sharma, 2014). From the various functions of polyamines and $\mathrm{H}_{2} \mathrm{O}_{2}$ studied till date, one can get a fair idea of the major roles played by them in priming for stress. Savvides et al. (2016) have argued about the role of some promising chemical agents such as sodium nitroprusside, $\mathrm{H}_{2} \mathrm{O}_{2}$, sodium hydrosulfide, melatonin, and polyamines that can potentially confer enhanced tolerance when plants are exposed to multiple abiotic stresses. In the present context it can be debated that increased polyamine accumulation in response to various stress conditions affects the epigenetic modifications of DNA and histones thus conferring stress tolerance. Plant polyamines create cellular responses during abiotic stress through modulation of ROS homeostasis via two distinct mechanisms (Takahashi and Kakehi, 2010). Firstly, polyamines promote ROS degradation by scavenging free radicals and activating antioxidant enzymes during stress conditions (Gupta et al., 2013a,b). Free polyamines are responsible for the detoxification of superoxide anions and $\mathrm{H}_{2} \mathrm{O}_{2}$, while the conjugated polyamines probably help in the scavenging of other ROS (Langebartels et al., 1991; Berberich et al., 2015). Kuznetsov and Shevyakova (2007) have reported that conjugated polyamines show more antioxidant ability than 


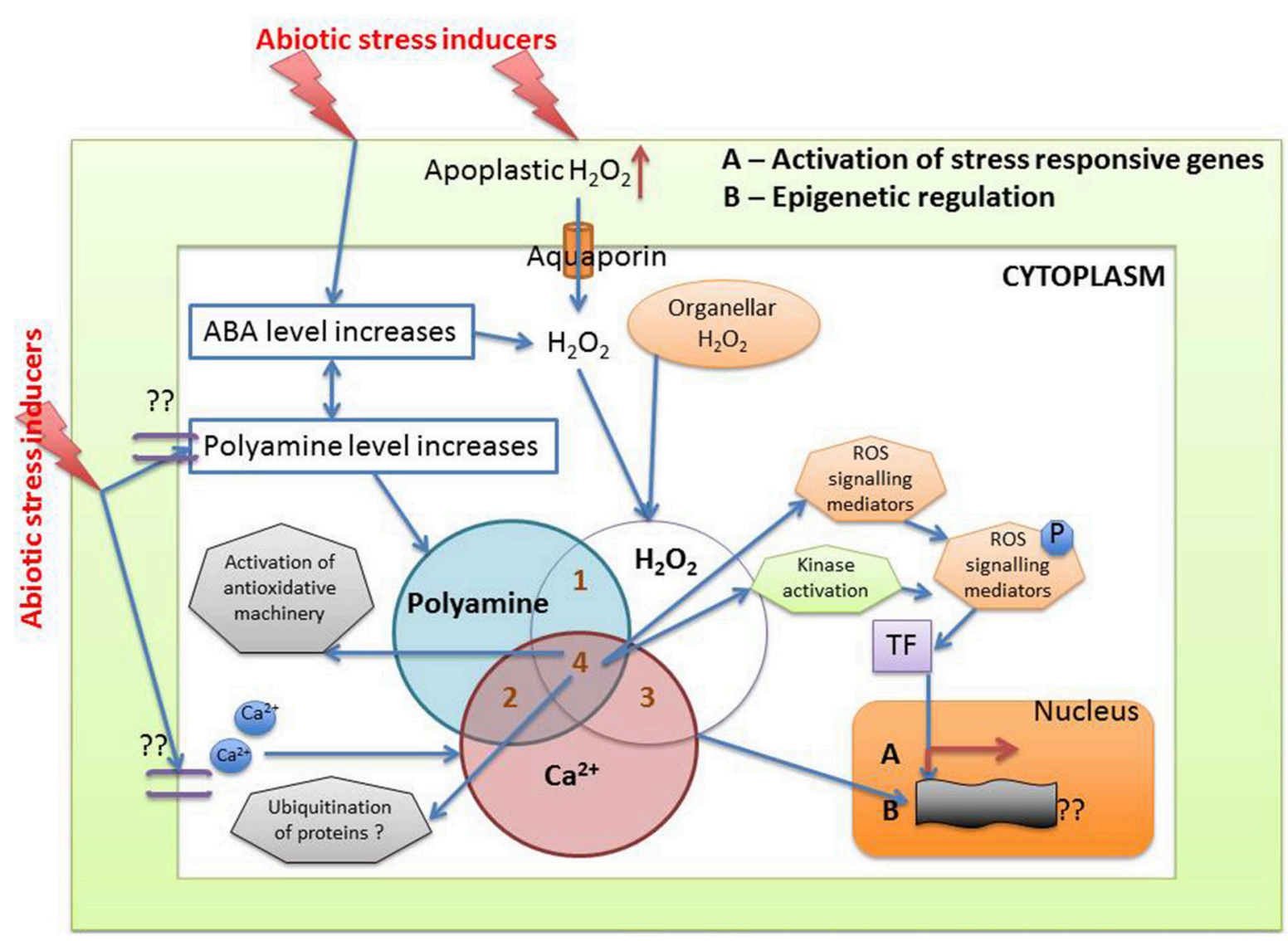

FIGURE 7 | Crosstalk between different metabolites during abiotic stress induced oxidative signaling (see text for details).

free polyamines. Secondly, polyamines promote ROS production through polyamine catabolism in the apoplast (Yoda et al., 2006; Mohapatra et al., 2010; Gupta et al., 2013a,b).

Mellidou et al. (2016) reported that a distinct crosstalk exists between peroxisomal polyamine oxidase and NADPH oxidase for maintaining ROS homeostasis in A. thaliana affecting their rate of respiration. They showed that the loss of function in AS-SAMDC salt-stressed plants resulted in an enormous increase of $\mathrm{H}_{2} \mathrm{O}_{2}$ compared to its control genotype. Moreover, higher SOD and elevated level of NADPH-oxidase activity in these SAMDC mutants emphasize the regulation of NADPHoxidase derived $\mathrm{H}_{2} \mathrm{O}_{2}$ by SAMDC during salinity-induced stress in Arabidopsis. Work done by the same group also showed the NADPH-oxidase dependent stimulation of oxygen consumption in Arabidopsis. Peroxisomal AtPAO3 shows a decreased oxygen consumption rate in stark comparison to the loss-of-function in Atpao3 Arabidopsis plants, which show increased consumption through the AOX pathway (Andronis et al., 2014). Diphenyleneiodonium iodide (DPI) [but not ascorbate (ASA)] attenuates this increase, suggesting that NADPH-oxidase is upstream of a respiratory increase mediated by AOX. It is interesting to note that overexpressed AtPAO3 plants show a balanced production of both $\mathrm{O}_{2}{ }^{\bullet-}$ and $\mathrm{H}_{2} \mathrm{O}_{2}$, while Atpao3 loss-of-function plants show a high $\mathrm{O}_{2}{ }^{\bullet-} / \mathrm{H}_{2} \mathrm{O}_{2}$ ratio. Their data clearly suggests a well-defined cross-talk between
NADPH-oxidase and AtPAO3 for balancing intracellular ROS affecting the cyt-c/AOX pathway. Lambeth and Neish (2014), while reviewing the relation of NOX (animal homolog of NADPH oxidase) and ROS, emphasized the role Nrf2/ARE signaling module in maintaining intracellular redox homeostasis in animals. However, till date no such pathway has been reported in plants. The activation of immune NADPH-oxidase by MAPK induced WRKY transcription factor throws some light on the transcriptional regulation of ROS in plants (Adachi et al., 2015).

From the above discussion the following mechanism can be hypothesized: abiotic stress increases apoplastic and organellar $\mathrm{H}_{2} \mathrm{O}_{2}$ along with increased synthesis of higher polyamines and second messengers like $\mathrm{Ca}^{2+}$. Increased polyamine adds further to the $\mathrm{H}_{2} \mathrm{O}_{2}$ pool, which triggers the activation of antioxidative machinery (enzymatic and non-enzymatic) in the plants. ABA levels are also known to increase during stress, and this can be instrumental in triggering ROS mediated signaling pathways via polyamines. Epigenetic regulation of stress response and involvement of protein degradation also cannot be ruled out. While it is difficult to determine which of these mechanisms, during abiotic stress, is the most important one, it can be envisaged that a well-coordinated defense mechanism comprising of polyamines, $\mathrm{Ca}^{2+}, \mathrm{H}_{2} \mathrm{O}_{2}$ take part in response to oxidative stress in plants (Figure 7). 


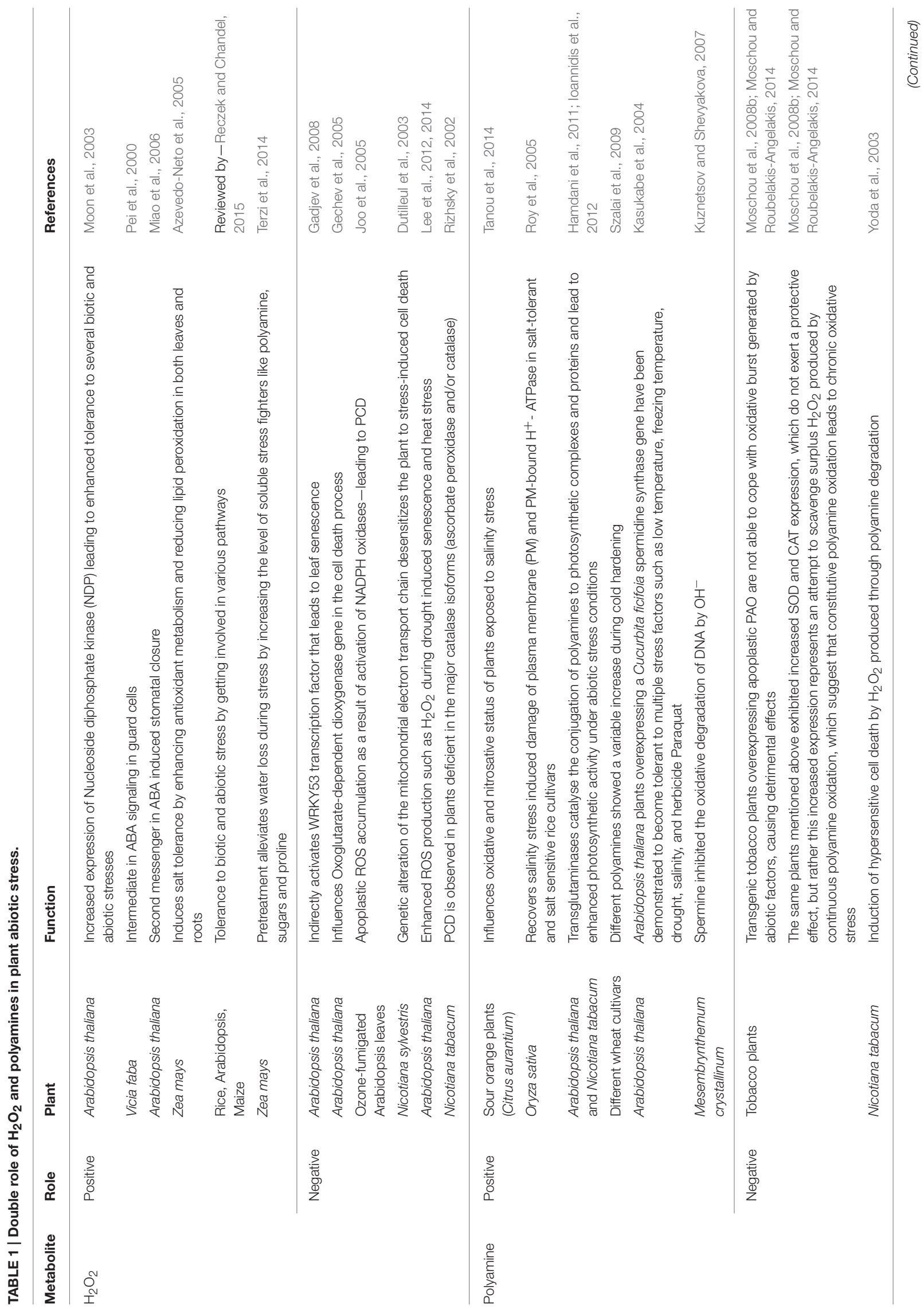


This review tries to present the dual role of both $\mathrm{H}_{2} \mathrm{O}_{2}$ and polyamines in a tabular form (Table $\mathbf{1}$ ). These evidences suggest that it is often "tricky" to establish a direct relationship between increased levels of polyamines $/ \mathrm{H}_{2} \mathrm{O}_{2}$ and abiotic stress tolerance. Pál et al. (2015) have suggested that the statement "the higher polyamine level the better" cannot be generalized and elevated polyamine content might be the cause of stress-induced injury and/or of some protective mechanisms. We would like to suggest that the intracellular level of $\mathrm{H}_{2} \mathrm{O}_{2}$ and different forms of polyamines act as the "safety valve" of the whole plant system that is delicately balanced depending on the type and duration of the stress, developmental stage of the plant, the genotype it belongs to, and the type of plant tissue affected. Further studies will enable us to get a better understanding of the role of polyamine and $\mathrm{H}_{2} \mathrm{O}_{2}$ in plants using several modern era technologies. We earnestly hope that the dual role of these two key players playing a silent role in the backdrop will be unveiled in the near future.

\section{CONCLUSION}

Environmental stresses are the key reasons behind massive crop loss throughout the world thus ravaging world agricultural economy. So the primary focus of the entire scientific world is to identify and implement strategies to overcome both abiotic and biotic stresses. In this process, they have identified roles of several molecules that are present within any normal living cell under non-stressful environmental conditions, playing the conventional roles that "Nature" designates them to play. But once the usual environment is replaced with a stressed one they start to function as stress alleviators. Two major examples of such molecules are polyamines and $\mathrm{H}_{2} \mathrm{O}_{2}$. Both of them have some demarcated responsibilities toward the cells they are produced in, but once they are exposed to an unfavorable environment they show a new dimension of their own which could not have been predicted earlier. Initially it was known that both polyamines and $\mathrm{H}_{2} \mathrm{O}_{2}$ play a significant role in maintaining physiological and biochemical processes in plants. However, their role in signaling and activating each other in response to stress is a new finding. Their correlation will be an intriguing topic for research in the near future. Some aspects of this interrelationship have already been discussed. But that is not enough to discern "whether polyamine and $\mathrm{H}_{2} \mathrm{O}_{2}$ functions as a dual-edged sword or not?" Despite the complexity plants are able to sort the stress signals and put up a well-organized defense mechanism. We would definitely be interested to know the intricate molecular mechanism that lies behind this unique inter-relationship and that is where the future prospect of this work lies.

\section{AUTHOR CONTRIBUTIONS}

KG contributed in writing the manuscript and drawing the figures. AS and MC contributed in initial drafting of the manuscript, developing some of the figures, and have contributed equally. BG designed and developed the entire manuscript and contributed in writing and drawing the figures. $\mathrm{KG}$ and $\mathrm{BG}$ are 
the corresponding authors and also contributed in research fund management.

\section{ACKNOWLEDGMENTS}

The authors acknowledge the support of technical facilities available at Presidency University, Kolkata.
Financial assistance from DBT (RGYI) (Govt. of India) (BT/PR6031/GBD/27/374/2012 dated 02/12/2013) and W.B. State DST (Govt. of West Bengal) (No. 167(Sanc.)/ST/P/S\&T/1G-12/2011 dated 06/05/2013) to BG and KG and DST-SERB (Govt. of India) (SB/FT/LS256/2012 dated 2nd May, 2013) to KG is also gratefully acknowledged.

\section{REFERENCES}

Abbasi, A. R., Hajirezaei, M., Hofius, D., Sonnewald, U., and Voll, L. M. (2007). Specific roles of alpha- and gamma-tocopherol in abiotic stress responses of transgenic tobacco. Plant Physiol. 143, 1720-1738. doi: 10.1104/pp.106.094771

Adachi, H., Nakano, T., Miyagawa, N., Ishihama, N., Yoshioka, M., Katou, Y., et al. (2015). WRKY transcription factors phosphorylated by MAPK regulate a plant immune NADPH oxidase in Nicotiana benthamiana. Plant Cell. 27, 2645-2663. doi: $10.1105 /$ tpc. 15.00213

Agrawal, G. K., Iwahashi, H., and Rakwal, R. (2003). Small GTPase 'Rop': molecular switch for plant defense responses. FEBS Lett. 546, 173-180. doi: 10.1016/S0014-5793(03)00646-X

Ahmad, P. (2014). Oxidative Damage to Plants - Antioxidant Networks and Signaling. New York, NY: Academic Press, Elsevier Inc.

Alcazar, R., Marco, F., Cuevas, J. C., Patron, M., Ferrando, A., Carrasco, P., et al. (2006). Involvement of polyamines in plant response to abiotic stress. Biotechnol. Lett. 28, 1867-1876. doi: 10.1007/s10529-006-9179-3

Andronis, E. A., Moschou, P. N., Toumi, I., and Roubelakis-Angelakis, K. A. (2014). Peroxisomal polyamine oxidase and NADPH-oxidase cross-talk for ROS homeostasis which affects respiration rate in Arabidopsis thaliana. Front. Plant Sci. 5:132. doi: 10.3389/fpls.2014.00132

Angelini, R., Cona, A., Federico, R., Fincato, P., Tavladoraki, P., and Tisi, A. (2010). Plant amine oxidases "on the move," an update. Plant Physiol. Biochem. 48, 560-564. doi: 10.1016/j.plaphy.2010.02.001

Anjum, N. A., Sofo, A., Scopa, A., Roychoudhury, A., Gill, S. S., Iqbal, M., et al. (2015). Lipids and proteins-major targets of oxidative modifications in abiotic stressed plants. Environ. Sci. Pollut. Res. Int. 22, 4099-4121. doi: 10.1007/s11356-014-3917-1

Asada, K. (2006). Production and scavenging of reactive oxygen species in chloroplasts and their functions. Plant Physiol. 141, 391-396. doi: $10.1104 /$ pp.106.082040

Asai, T., Stone, J. M., Heard, J. E., Kovtun, Y., Yorgey, P., Sheen, J., et al. (2000). Fumonisin B1-induced cell death in arabidopsis protoplasts requires jasmonate-,ethylene-, and salicylate-dependent signalling pathways. Plant Cell. 12, 1823-1836. doi: 10.1105/tpc.12.10.1823

Azevedo-Neto, A. D., Prisco, J. T., Eneas-Filho, J., Medeiros, J. V. R., and Gomes-Filho, E. (2005). Hydrogen peroxide pre-treatment induces salt stress acclimation in maize plants. J. Plant Physiol. 162, 1114-1122. doi: 10.1016/j.jplph.2005.01.007

Bagni, N., and Tassoni, A. (2001). Biosynthesis, oxidation and conjugation of aliphatic polyamines in plants. Amino Acids 20, 301-317. doi: 10.1007/s007260170046

Baxter, A., Mittler, R., and Suzuki, N. (2014). ROS as key players in plant stress signalling. J. Exp. Bot. 65, 1229-1240. doi: 10.1093/jxb/ert375

Begara-Morales, J. C., Sánchez-Calvo, B., Chaki, M., Valderrama, R., Mata-Pérez, C., López-Jaramillo, J., et al. (2013). Dual regulation of cytosolic ascorbate peroxidase (APX) by tyrosine nitration and S-nitrosylation. J. Exp. Bot. 65, 527-538. doi: 10.1093/jxb/ert396

Berberich, T., Sagor, G. H. M., and Kusano, T. (2015). "Polyamines in plant stress response," in Polyamines, eds T. Kusano and H. Suzuki (Tokyo: Springer Japan), 155-168. doi: 10.1007/978-4-431-55212-3_13

Bhattacharjee, S. (2005). Reactive oxygen species and oxidative burst: roles in stress, senescence and signal transduction in plant. Curr. Sci. 89, 1113-1121.

Bhattacharjee, S. (2012). An inductive pulse of hydrogen peroxide pretreatment restores redox-homeostasis and oxidative membrane damage under extremes

of temperature in two rice cultivars. Plant Growth Regul. 68, 395-410. doi: 10.1007/s10725-012-9728-9

Bolouri-Moghaddam, M. R., Le Roy, K., Xiang, L., Rolland, F., and Van den Ende, W. (2010). Sugar signalling and antioxidant network connections in plant cells. FEBS J. 277, 2022-2037. doi: 10.1111/j.1742-4658.2010.07633.x

Bright, J., Desikan, R., Hancock, J. T., Weir, I. S., and Neill, S. J. (2006). ABAinduced NO generation and stomatal closure in Arabidopsis are dependent on $\mathrm{H}_{2} \mathrm{O}_{2}$ synthesis. Plant J. 45, 113-122. doi: 10.1111/j.1365-313X.2005.02615.x

Bruce, T. J., Matthes, M. C., Napier, J. A., and Pickett, J. A. (2007). Stressful "memories" of plants: evidence and possible mechanisms. Plant Sci. 173, 603-608. doi: 10.1016/j.plantsci.2007.09.002

Capone, C., Cervelli, M., Angelucci, E., Colasanti, M., Macone, A., Mariottini, P., et al. (2013). A role for spermine oxidase as a mediator of reactive oxygen species production in HIV-Tat-induced neuronal toxicity. Free Radic. Biol. Med. 63, 99-107. doi: 10.1016/j.freeradbiomed.2013.05.007

Cona, A., Rea, G., Botta, M., Corelli, F., Federico, R., and Angelini, R. (2006). Flavin-containing polyamine oxidase is a hydrogen peroxide source in the oxidative response to the protein phosphatase inhibitor cantharidin in Zea mays L. J. Exp. Bot. 57, 2277-2289. doi: 10.1093/jxb/erj195

Costa, A., Drago, I., Behera, S., Zottini, M., Pizzo, P., Schroeder, J., et al. (2010). $\mathrm{H}_{2} \mathrm{O}_{2}$ in plant peroxisomes: an in vivo analysis uncovers a $\mathrm{Ca}^{2+}$-dependent scavenging system. Plant J. 62, 760-772. doi: 10.1111/j.1365-313X.2010. 04190.x

Dat, J., Vandenabeele, S., Vranova, E., van Montagu, M., Inze, D., and van Breusegem, F. (2000). Dual action of the active oxygen species during plant stress responses. Cell. Mol. Life Sci. 57, 779-795. doi: 10.1007/s000180050041

Davletova, S., Rizhsky, L., Liang, H., Shengqiang, Z., Oliver, D. J., Coutu, J., et al. (2005). Cytosolic ascorbate peroxidase 1 is a central component of the reactive oxygen gene network of Arabidopsis. Plant Cell 17, 268-281. doi: $10.1105 /$ tpc.104.026971

Della Mea, M., Caparros-Ruiz, D., Claparols, I., Serafini-Fracassini, D., and Rigau, J. (2004). AtPnglp. The first plant transglutaminase. Plant. Physiol. 135, 2046-2054. doi: 10.1104/pp.104.042549

Delrio, L. A., Sandalio, L. M., Palma, J. M., Bueno, P., and Corpas, F. J. (1992). Metabolism of oxygen radicals in peroxisomes and cellular implications. Free Rad. Biol. Med. 13, 557-580. doi: 10.1016/0891-5849(92)90150-F

Demidchik, V., Shabala, S. N., and Davies, J. M. (2007). Spatial variation in $\mathrm{H}_{2} \mathrm{O}_{2}$ response of Arabidopsis thaliana root epidermal $\mathrm{Ca}^{2+}$ flux and plasma membrane $\mathrm{Ca}^{2+}$ channels. Plant J. 49, 377-386. doi: 10.1111/j.1365313X.2006.02971.x

Desikan, R., Cheung, M. K., Bright, J., Henson, D., Hancock, J. T., and Neill, S. J. (2004). ABA, hydrogen peroxide and nitric oxide signalling in stomatal guard cells. J. Exp. Bot. 55, 205-212. doi: 10.1093/jxb/erh033

Desikan, R. S., Mackerness, A. H., Hancock, J. T., and Neill, S. J. (2001). Regulation of the Arabidopsis transcriptome by oxidative stress. Plant Physiol. 127, 159-172. doi: 10.1104/pp.127.1.159

Dietz, K. J., Mittler, R., and Noctor, G. (2016). Recent progress in understanding the role of reactive oxygen species in plant cell signaling. Plant Physiol. 171, 1535-1539. doi: 10.1104/pp.16.00938

Dutilleul, C., Garmier, M., Noctor, G., Mathieu, C. D., Chétrit, P., Foyer, C. H., et al. (2003). Leaf mitochondria modulate whole cell redox homeostasis, set antioxidant capacity and determine stress resistance through altered signaling and diurnal regulation. Plant Cell. 15, 1212-1226. doi: 10.1105/tpc.009464

Edreva, A. M., Velikova, V. B., and Tsonev, T. D. (2007). Phenylamides in plants. Russ. J. Plant Physiol. 54, 287-301. doi: 10.1134/S1021443707030016 
Fan, Y., and Huang, Y. (2012). The effective peroxidase-like activity of chitosan functionalized $\mathrm{CoFe}_{2} \mathrm{O}_{4}$ nanoparticles for chemiluminescence sensing of hydrogen peroxide and glucose. Analyst 137, 1225-1231. doi: $10.1039 / \mathrm{c} 2 \mathrm{an} 16105 \mathrm{~b}$

Farooq, M., Wahid, A., and Lee, D. J. (2009). Exogenously applied polyamines increase drought tolerance of rice by improving leaf water status, photosynthesis and membrane properties. Acta Physiol. Plant. 31, 937-945. doi: 10.1007/s11738-009-0307-2

Ferrando, A., Carrasco, P., Cuevas, J. C., Altabella, T., and Tiburcio, A. F. (2004). "Integrated molecular analysis of the poly-amine pathway in abiotic stress signalling," in Nitrogen Acquisition and Assimilation in Higher Plants, eds S. Amancio and I. Stulen (Dordrecht: Kluwer Academic Publisher), 207-230.

Foyer, C. H., and Noctor, G. (2005). Oxidant and antioxidant signalling in plants: a re-evaluation of the concept of oxidative stress in a physiological context. Plant Cell Environ. 28, 1056-1071. doi: 10.1111/j.1365-3040.2005.01327.x

Gadjev, I., Stone, J. M., and Gechev, T. S. (2008). Programmed cell death in plants: new insights into redox regulation and the role of hydrogen peroxide. Int. Rev. Cell Mol. Biol. 270, 87-144. doi: 10.1016/S1937-6448(08)01403-2

Gapper, C., and Dolan, L. (2006). Control of plant development by reactive oxygen species. Plant Physiol. 141, 341-345. doi: 10.1104/pp.106.079079

Gechev, T. S., and Hille, J. (2005). Hydrogen peroxide as a signal controlling plant programmed cell death. J. Cell Biol. 168, 17-20. doi: 10.1083/jcb.200409170

Gechev, T. S., Minkov, I. N., and Hille, J. (2005). Hydrogen peroxide-induced cell death in Arabidopsis: transcriptional and mutant analysis reveals a role of an oxoglutarate-dependent dioxygenase gene in the cell death process. IUBMB Life 57, 181-188. doi: 10.1080/15216540500090793

Gill, S. S., and Tuteja, N. (2010). Polyamines and abiotic stress tolerance in plants. Plant Signal. Behav. 5, 26-33. doi: 10.4161/psb.5.1.10291

Giraud, E., Ho, L. H., Clifton, R., Carroll, A., Estavillo, G., Tan, Y. F., et al. (2008). The absence of ALTERNATIVE OXIDASE1a in Arabidopsis results in acute sensitivity to combined light and drought stress. Plant Physiol. 147, 595-610. doi: 10.1104/pp.107.115121

Gong, B., Wang, X., Wei, M., Yang, F., Li, Y., and Shi, Q. (2016). Overexpression of S-adenosylmethionine synthetase 1 enhances tomato callus tolerance to alkali stress through polyamine and hydrogen peroxide cross-linked networks. Plant Cell Tiss. Org. Cult. 124, 377-391. doi: 10.1007/s11240-015-0901-5

Groppa, M. D., and Benavides, M. P. (2008). Polyamines and abiotic stress: recent advances. Amino Acids 34, 35-45. doi: 10.1007/s00726-007-0501-8

Guo, Z., Tan, J., Zhuo, C., Wang, C., Xiang, B., and Wang, Z. (2014). Abscisic acid, $\mathrm{H}_{2} \mathrm{O}_{2}$ and nitric oxide interactions mediated cold-induced $\mathrm{S}$-adenosylmethionine synthetase in Medicago sativa subsp. falcata that confers cold tolerance through up-regulating polyamine oxidation. Plant Biotechnol. J. 12, 601-612. doi: $10.1111 /$ pbi. 12166

Gupta, B., Gupta, K., and Huang, B. (2014). "Role of polyamines in plant abiotic stress responses," in Handbook of Plant and Crop Physiology, 3rd Edn., ed M. Pessarakli (Boca Raton, FL: CRC Press), 369-388.

Gupta, K., Dey, A., and Gupta, B. (2013a). Plant polyamines in abiotic stress responses. Acta Physiol. Plant 35, 2015-2036. doi: 10.1007/s11738-013-1239-4

Gupta, K., Dey, A., and Gupta, B. (2013b). Polyamines and their role in plant osmotic stress tolerance. Clim. Change Plant Abiotic Stress Tolerance 2, 1053-1072. doi: 10.1002/9783527675265.ch40

Gupta, K., Gupta, B., Ghosh, B., and Sengupta, D. N. (2012). Spermidine and abscisic acid-mediated phosphorylation of a cytoplasmic protein from rice root in response to salinity stress. Acta Physiol. Plant. 34, 29-40. doi: 10.1007/s11738-011-0802-0

Gupta, S., Agarwal, V. P., and Gupta, N. K. (2012). Efficacy of putrescine and benzyladenine on photosynthesis and productivity in relation to drought tolerance in wheat (Triticum aestivum L.). Physiol. Mol. Biol. Plants 18, 331-336. doi: 10.1007/s12298-012-0123-9

Hamdani, S., Yaakoubi, H., and Carpentier, R. (2011). Polyamines interaction with thylakoid proteins during stress. J. Photochem. Photobiol. B 104, 314-319. doi: 10.1016/j.jphotobiol.2011.02.007

Han, S., Fang, L., Ren, X., Wang, W., and Jiang, J. (2015). MPK6 controls $\mathrm{H}_{2} \mathrm{O}_{2}$ induced root elongation by mediating $\mathrm{Ca}^{2+}$ influx across the plasma membrane of root cells in Arabidopsis seedlings. New Phytol. 205, 695-706. doi: 10.1111/nph.12990

Hanfrey, C., Sommer, S., Mayer, M. J., Burtin, D., and Michael, A. J. (2001). Arabidopsis polyamine biosynthesis: absence of ornithine decarboxylase and the mechanism of arginine decarboxylase activity. Plant. J. 27, 551-560. doi: 10.1046/j.1365-313X.2001.01100.x

Hänsch, R., Lang, C., Riebeseel, E., Lindigkeit, R., Gessler, A., Rennenberg, H., et al. (2006). Plant sulfite oxidase as novel producer of $\mathrm{H}_{2} \mathrm{O}_{2}$ combination of enzyme catalysis with a subsequent non-enzymatic reaction step. J. Biol. Chem. 281, 6884-6888. doi: 10.1074/jbc.M513054200

Hossain, M. A., Munemasa, S., Uraji, M., Nakamura, Y., Mori, I. C., and Murata, Y. (2011). Involvement of endogenous abscisic acid in methyl jasmonateinduced stomatal closure in Arabidopsis. Plant Physiol. 156, 430-438. doi: 10.1104/pp.111.172254

Hsu, Y. T., and Kao, C. H. (2007). Cadmium induced oxidative damage in rice leaves reduced by polyamines. Plant Soil 291, 27-37. doi: 10.1007/s11104-0069171-7

Huang, A. X., Wang, Y. S., She, X. P., Mu, J., and Zhao, J. L. (2015). Copper amine oxidase-catalysed hydrogen peroxide involves production of nitric oxide in darkness-induced stomatal closure in broad bean. Funct. Plant Biol. 42, 1057-1067. doi: 10.1071/FP15172

Hussain, S. S., Ali, M., Ahmad, M., and Siddique, K. H. (2011). Polyamines: natural and engineered abiotic and biotic stress tolerance in plants. Biotechnol. Adv. 29, 300-311. doi: 10.1016/j.biotechadv.2011.01.003

Iakimova, E. T., and Woltering, E. J. (2015). Nitric oxide prevents wound-induced browning and delays senescence through inhibition of hydrogen peroxide accumulation in fresh-cut lettuce. Innov. Food Sci. Emerg. 30, 157-169. doi: 10.1016/j.ifset.2015.06.001

Iannone, M. F., Rosales, E. P., Groppa, M. D., and Benavides, M. P. (2013). $\mathrm{H}_{2} \mathrm{O}_{2}$ involvement in polyamine-induced cell death in tobacco leaf discs. J. Plant Growth Regul. 32, 745-757. doi: 10.1007/s00344-0139341-9

Ioannidis, N. E., Cruz, J. A., Kotzabasis, K., and Kramer, D. M. (2012). Evidence that putrescine modulates the higher plant photosynthetic proton circuit. PLoS ONE 7:e29864. doi: 10.1371/journal.pone.0029864

Jahan, A. A., and Anis, M. (2014). Changes in antioxidative enzymatic responses during acclimatization of in vitro raised plantlets of Cardiospermum halicacabum L. against oxidative stress. J. Plant Physiol. Pathol. 4, 2. doi: 10.4172/2329-955X.1000137

Janowitz, T., Kneifel, H., and Piotrowski, M. (2003). Identification and characterization of plant agmatine iminohydrolase, the last missing link in polyamine biosynthesis of plants. FEBS Lett. 544, 258-226. doi: 10.1016/S00145793(03)00515-5

Jaspers, P., and Kangasjarvi, J. (2010). Reactive oxygen species in abiotic stress signalling. Physiol. Plant. 138, 405-413. doi: 10.1111/j.1399-3054.2009. 01321.x

Jisha, K. C., and Puthur, J. T. (2016). Seed priming with BABA ( $\beta$-amino butyric acid): a cost-effective method of abiotic stress tolerance in Vigna radiata (L.) Wilczek. Protoplasma 253, 277-289. doi: 10.1007/s00709-015-0804-7

Jisha, K. C., Vijayakumari, K., and Puthur, J. T. (2013). Seed priming for abiotic stress tolerance: an overview. Acta Physiol. Plant. 35, 1381-1396. doi: 10.1007/s11738-012-1186-5

Joo, J. H., Wang, S., Chen, J. G., Jones, A. M., and Fedoroff, N. V. (2005). Different signaling and cell death roles of heterotrimeric $G$ protein a and b subunits in the Arabidopsis oxidative stress response to ozone. Plant Cell. 17, 957-970. doi: $10.1105 /$ tpc. 104.029603

Kakehi, J. I., Kuwashiro, Y., Niitsu, M., and Takahashi, T. (2008). Thermospermine is required for stem elongation in Arabidopsis thaliana. Plant Cell Physiol. 49, 1342-1349. doi: 10.1093/pcp/pcn109

Kasukabe, Y., He, L., Nada, K., Misawa, S., Ihara, I., and Tachibana, S. (2004). Overexpression of spermidine synthase enhances tolerance to multiple environmental stresses and up-regulates the expression of various stress regulated genes in transgenic Arabidopsis thaliana. Plant Cell Physiol. 45, 712-722. doi: $10.1093 / \mathrm{pcp} / \mathrm{pch} 083$

Kilian, J., Whitehead, D., Horak, J., Wanke, D., Weinl, S., Batistic, O., et al. (2007) The AtGenExpress global stress expression data set: protocols, evaluation and model data analysis of UV-B light, drought and cold stress responses. Plant J. 50, 347-363. doi: 10.1111/j.1365-313X.2007.03052.x

Kuznetsov, V. V., Rakitin, V. Y., Sadomov, N. G., Dam, D. V., Stetsenko, L. A., and Shevyakova, N. I. (2002). Do polyamines participate in the long-distance translocation of stress signals in plants? Russ. J. Plant Physiol. 49, 120-130. doi: 10.1023/A:1013776631284 
Kuznetsov, V. V., and Shevyakova, N. I. (2007). Polyamines and stress tolerance of plants. Plant Stress. 1, 50-71.

Lambeth, J. D., and Neish, A. S. (2014). Nox enzymes and new thinking on reactive oxygen: a double-edged sword revisited. Annu. Rev. Pathol. 9, 119-145. doi: 10.1146/annurev-pathol-012513-104651

Langebartels, C., Kerner, K., Leonardi, S., Schraudner, M., Trost, M., Heller, W., et al. (1991). Biochemical-plant responses to ozone.1. differential induction of polyamine and ethylene biosynthesis in tobacco. Plant Physiol. 95, 882-889. doi: $10.1104 /$ pp.95.3.882

Lee, S., Lee, H. J., Huh, S. U., Paek, K. H., Ha, J. H., and Park, C. M. (2014). The Arabidopsis NAC transcription factor NTL4 participates in a positive feedback loop that induces programmed cell death under heat stress conditions. Plant Sci. 227, 76-83. doi: 10.1016/j.plantsci.2014.07.003

Lee, S., Seo, P. J., Lee, H. J., and Park, C. M. (2012). A NAC transcription factor NTL4 promotes reactive oxygen species production during drought-induced leaf senescence in Arabidopsis. Plant J. 70, 831-844. doi: 10.1111/j.1365313X.2012.04932.x

Li, H., Shen, J. J., Zheng, Z. L., Lin, Y., and Yang, Z. (2001). The Rop GTPase switch controls multiple developmental processes in Arabidopsis. Plant Physiol. 126, 670-684. doi: 10.1104/pp.126.2.670

Li, Z., Zhang, Y., Peng, D., Wang, X., Peng, Y., He, X., et al. (2015). Polyamine regulates tolerance to water stress in leaves of white clover associated with antioxidant defense and dehydrin genes via involvement in calcium messenger system and hydrogen peroxide signaling. Front. Physiol. 6:280. doi: $10.3389 /$ fphys.2015.00280

Liao, W. B., Xiao, H. L., and Zhang, M. L. (2010). Effect of nitric oxide and hydrogen peroxide on adventitious root development from cuttings of groundcover chrysanthemum and associated biochemical changes. J. Plant Growth Regul. 29, 338-348. doi: 10.1007/s00344-010-9140-5

Lin, A. H., Wang, Y. Q., Tang, J. Y., Xue, P., Li, C. L., Liu, L. C., et al. (2012). Nitric oxide and protein S-Nitrosylation are integral to hydrogen peroxide-induced leaf cell death in Rice. Plant Physiol. 158, 451-464. doi: 10.1104/pp.111.184531

Liu, X., Wang, L., Liu, L., Guo, Y., and Ren, H. (2011). Alleviating effect of exogenous nitric oxide in cucumber seedling against chilling stress. Afr. J. Biotechnol. 10, 4380-4386. doi: 10.5897/AJB10.812

$\mathrm{Ma}, \mathrm{S}$., and Bohnert, H. J. (2007). Integration of Arabidopsis thaliana stress-related transcript profiles, promoter structures, and cell-specific expression. Genome Biol. 8:R49. doi: 10.1186/gb-2007-8-4-r49

Mapelli, S., Brambilla, I. M., Radyukina, N. L., Ivanov, Y. V., Kartashov, A. V., Reggiani, R., et al. (2008). Free and bound polyamines changes in different plants as a consequence of UV-B light irradiation. Gen. Appl. Plant Physiol. 34, $55-66$.

Mellidou, I., Moschou, P. N., Ioannidis, N. E., Pankou, C., GẢmes, K., Valassakis, C., et al. (2016). Silencing S-Adenosyl-L-Methionine Decarboxylase (SAMDC) in Nicotiana tabacum points at a polyamine-dependent tradeoff between growth and tolerance responses. Front. Plant Sci. 7:379. doi: 10.3389/fpls.2016.00379

Miao, Y., Lv, D., Wang, P., Wang, X. C., Chen, J., Miao, C., et al. (2006). An Arabidopsis glutathione peroxidase functions as both a redox transducer and a scavenger in abscisic acid and drought stress responses. Plant Cell. 18, 2749-2766. doi: 10.1105/tpc.106.044230

Miller, G., Shulaev, V., and Mittler, R. (2008). Reactive oxygen signalling and abiotic stress. Plant Physiol. 133, 481-489. doi: 10.1111/j.1399-3054.2008.01090.x

Miller, G., Suzuki, N., Ciftci-Yilmaz, S., and Mittler, R. (2010). Reactive oxygen species homeostasis and signalling during drought and salinity stresses. Plant Cell Environ. 33, 453-467. doi: 10.1111/j.1365-3040.2009.02041.x

Mittler, R. (2006). Abiotic stress, the field environment and stress combination. Trends Plant Sci. 1, 15-19. doi: 10.1016/j.tplants.2005.11.002

Mittler, R., Vanderauwera, S., Suzuki, N., Miller, G., Tognetti, V. B., Vandepoele, K., et al. (2011). ROS signaling: the new wave? Trends Plant Sci. 16, 300-309. doi: 10.1016/j.tplants.2011.03.007

Mittova, V., Volokita, M., and Guy, M. (2015). "Antioxidative systems and stress tolerance: insight from wild and cultivated tomato species," in Reactive Oxygen and Nitrogen Species Signaling and Communication in Plants, eds K. J. Gupta and A. U. Igamberdiev (Springer International Publishing), 89-131. doi: 10.1007/978-3-319-10079-1_6
Mohapatra, S., Minocha, R., Long, S., and Minocha, S. C. (2010). Transgenic manipulation of a single polyamine in poplar cells affects the accumulation of all amino acids. Amino Acids 38, 1117-1129. doi: 10.1007/s00726-009-0322-z

Moller, I. M., Jensen, P. E., and Hansson, A. (2007). Oxidative modifications to cellular components in plants. Ann. Rev. Plant Biol. 58, 459-481. doi: 10.1146/annurev.arplant.58.032806.103946

Moon, H., Lee, B., Choi, G., Shin, D., Prasad, D. T., Lee, O., et al. (2003). NDP kinase 2 interacts with two oxidative stress-activated MAPKs to regulate cellular redox state and enhances multiple stress tolerance in transgenic plants. Proc. Natl. Acad. Sci. U.S.A. 100, 358-363. doi: 10.1073/pnas.252641899

Moschou, P. N., Delis, I. D., Paschalidis, K. A., and Roubelakis-Angelakis, K. A. (2008b). Transgenic tobacco plants overexpressing polyamine oxidase are not able to cope with oxidative burst generated by abiotic factors. Physiol. Plant. 133, 140-156. doi: 10.1111/j.1399-3054.2008.01049.x

Moschou, P. N., Paschalidis, K., and Roubelakis-Angelakis, K. (2008a). Plant polyamine catabolism: the state of the art. Plant Signal. Behav. 12, 1061-1066. doi: $10.4161 /$ psb.3.12.7172

Moschou, P. N., and Roubelakis-Angelakis, K. A. (2014). Polyamines and programmed cell death. J. Exp. Bot. 65, 1285-1296. doi: 10.1093/jxb/ ert373

Moschou, P. N., Wu, J., Cona, A., Tavladoraki, P., Angelini, R., and RoubelakisAngelakis, K. A. (2012). The polyamines and their catabolic products are significant players in the turnover of nitrogenous molecules in plants. J. Exp. Bot. 63, 5003-5015. doi: 10.1093/jxb/ers202

Munné-Bosch, S. (2007). $\alpha$-tocopherol: a multifaceted molecule in plants. Vitam. Horm. 76, 375-392. doi: 10.1016/S0083-6729(07)76014-4

Munné-Bosch, S., Queval, G., and Foyer, C. H. (2013). The impact of global change factors on redox signaling underpinning stress tolerance. Plant Physiol. 161, 5-19. doi: 10.1104/pp.112.205690

Nahar, K., Hasanuzzaman, M., Rahman, A., Alam, M., Mahmud, J. A., Suzuki, T., et al. (2016). Polyamines confer salt tolerance in mung bean (Vigna radiata L.) by reducing sodium uptake, improving nutrient homeostasis, antioxidant defense and methylglyoxal detoxification systems. Front. Plant Sci. 7:1104. doi: 10.3389/fpls.2016.01104

Nayyar, H., and Chander, S. (2004). Protective effects of polyamines against oxidative stress induced by water and cold stress in chickpea. J. Agron. Crop Sci. 190, 355-365. doi: 10.1111/j.1439-037X.2004.00106.x

Neill, S. J., Desikan, R., and Hancock, J. (2002). Hydrogen peroxide signalling. Curr. Opin. Plant Biol. 5, 388-395. doi: 10.1016/S1369-5266(02) 00282-0

Noctor, G., Mhamdi, A., Chaouch, S., Han, Y. I., Neukermans, J., Marquez-Garcia, B., et al. (2012). Glutathione in plants: an integrated overview. Plant Cell Environ. 35, 454-484. doi: 10.1111/j.1365-3040.2011. 02400.x

Ono, Y., Kim, D. W., Watanabe, K., Sasaki, A., Niitsu, M., Berberich, T., et al. (2012). Constitutively and highly expressed Oryza sativa polyamine oxidases localize in peroxisomes and catalyze polyamine back conversion. Amino Acids 42, 867-876. doi: 10.1007/s00726-011-1002-3

Pál, M., Szalai, G., and Janda, T. (2015). Speculation: polyamines are important in abiotic stress signaling. Plant Sci. 237, 16-23. doi: 10.1016/j.plantsci.2015.05.003

Pan, X., Niu, G., and Liu, H. (2003). Microwave-assisted extraction of tea polyphenols, tea caffeine from green tea leaves. Chem. Eng. Process. 42, 129-133. doi: 10.1016/S0255-2701(02)00037-5

Paulsen, C. E., and Carroll, K. S. (2010). Orchestrating redox signalling networks through regulatory cysteine switches. ACS Chem. Biol. 5, 47-62. doi: $10.1021 / \mathrm{cb} 900258 \mathrm{z}$

Pei, Z. M., Murata, Y., Benning, G., Thomine, S., Klüsener, B., Allen, G. J., et al. (2000). Calcium channels activated by hydrogen peroxide mediate abscisic acid signalling in guard cells. Nature 406, 731-734. doi: 10.1038/35021067

Piotrowski, M., Janowitz, T., and Kneifel, H. (2003). Plant C-N hydrolases and the identification of a plant N-carba-moylputrescine amidohydrolase involved in poly- amine biosynthesis. J. Biol. Chem. 278, 1708-1712. doi: 10.1074/jbc.M205699200

Pottosin, I., and Shabala, S. (2014). Polyamines control of cation transport across plant mem-branes: implications for ion homeostasis and abiotic stress signalling. Front. Plant Sci. 5:154. doi: 10.3389/fpls.2014.00154 
Radhakrishnan, R., and Lee, I. J. (2013). Ameliorative effects of spermine against osmotic stress through antioxidants and abscisic acid changes in soybean pods and seeds. Acta Physiol. Plant. 35, 263-269. doi: 10.1007/s11738-0121072-1

Reczek, C. R., and Chandel, N. S. (2015). ROS-dependent signal transduction. Curr. Opin. Cell Biol. 33, 8-13. doi: 10.1016/j.ceb.2014.09.010

Richards, S. L., Laohavisit, A., Mortimer, J. C., Shabala, L., Swarbreck, S. M., Shabala, S., et al. (2014). Annexin 1 regulates the $\mathrm{H}_{2} \mathrm{O}_{2}$ induced calcium signature in Arabidopsis thaliana roots. Plant J. 77, 136-145. doi: $10.1111 /$ tpj. 12372

Rizhsky, L., Hallak-Herr, E., Van Breusegem, F., Rachmilevitch, S., Barr, J. E., Rodermel, S., et al. (2002). Double antisense plants lacking ascorbate peroxidase and catalase are less sensitive to oxidative stress than single antisense plants lacking ascorbate peroxidase or catalase. Plant J. 32, 329-342. doi: 10.1046/j.1365-313X.2002.01427.x

Roy, P., Niyogi, K., Sengupta, D. N., and Ghosh, B. (2005). Spermidine treatment to rice seedlings recovers salinity stress induced damage of Plasma membrane and PM-bound H+- ATPase in salt-tolerant and salt sensitive Rice cultivars. Plant Sci. 168, 583-591. doi: 10.1016/j.plantsci.2004. 08.014

Saha, J., Brauer, E. K., Sengupta, A., Popescu, S. C., Gupta, K., and Gupta, B. (2015). Polyamines as redox homeostasis regulators during salt stress in plants. Front. Environ. Sci. 3:21. doi: 10.3389/fenvs.2015.00021

Sakamoto, A., Terui, Y., Yoshida, T., Yamamoto, T., Suzuki, H., Yamamoto, K., et al. (2015). Three members of polyamine modulon under oxidative stress conditions: two transcription factors (SoxR and EmrR) and a glutathione synthetic enzyme (GshA). PLoS ONE 10:e0124883. doi: 10.1371/journal.pone. 0124883

Saleethong, P., Sanitchon, J., Kong-Ngern, K., and Theerakulpisut, P. (2013). Effects of exogenous spermidine (Spd) on yield, yield-related pretreatment and mineral composition of rice (Oryza sativa L. ssp. indica) grains under salt stress. Aust. J. Crop. Sci. 7, 1293-1301.

Sano, H. (2010). Inheritance of acquired traits in plants: reinstatement of Lamarck. Plant Signal. Behav. 5, 346-348. doi: 10.4161/psb.5.4.10803

Savvides, A., Ali, S., Tester, M., and Fotopoulos, V. (2016). Chemical priming of plants against multiple abiotic stresses: mission possible? Trends Plant Sci. 21, 329-340. doi: 10.1016/j.tplants.2015.11.003

Schieber, M., and Chandel, N. S. (2014). ROS function in redox signaling and oxidative stress. Curr. Biol. 24, R453-R462. doi: 10.1016/j.cub.2014. 03.034

Sengupta, A., Chakraborty, M., Saha, J., Gupta, B., and Gupta, K. (2016). "Polyamines: osmoprotectants in plant abiotic stress adaptation," in Osmolytes and Plants Acclimation to Changing Environment: Emerging Omics Technologies, eds N. Iqbal, R. Nazar, and N. A. Khan (Springer India), 97-127. doi: 10.1007/978-81-322-2616-1_7

Serrano, I., Romero-Puertas, M. C., Rodríguez-Serrano, M., Sandalio, L. M., and Olmedilla, A. (2012). Peroxynitrite mediates programmed cell death both in papillar cells and in self-incompatible pollen in the olive (Olea europaea L.). J. Exp. Bot. 63, 1479- 1493. doi: 10.1093/jxb/err392

Sewelam, N., Jaspert, N., Kelen, K. V. D., Schmitz, J., Frerigmann, H., Tognetti, V. B., et al. (2014). Spatial $\mathrm{H}_{2} \mathrm{O}_{2}$ signaling specificity: $\mathrm{H}_{2} \mathrm{O}_{2}$ from chloroplasts and peroxisomes differentially modulates the plant transcriptome. Mol. Plant. 7, 1191-1210. doi: 10.1093/mp/ssu070

Shao, C., Li, Q., Chen, S., Zhang, P., Lian, J., Hu, Q., et al. (2014). Epigenetic modification and inheritance in sexual reversal of fish. Genome Res. 24, 604-615. doi: 10.1101/gr.162172.113

Sharma, A. (2014). Novel transcriptome data analysis implicates circulating microRNAs in epigenetic inheritance in mammals. Gene 538, 366-372. doi: 10.1016/j.gene.2014.01.051

Sharma, P., and Dubey, R. S. (2007). Involvement of oxidative stress and role of antioxidative defence system in growing rice seedlings exposed to toxic concentrations of aluminium. Plant Cell Rep. 26, 2027-2038. doi: 10.1007/s00299-007-0416-6

Sharma, P., Jha, A. B., Dubey, R. S., and Pessarakli, M. (2012). Reactive oxygen species, oxidative damage, and antioxidative defense mechanism in plants under stressful conditions. J. Bot. 2012:217037. doi: 10.1155/2012/ 217037
Shen, W., Nada, K., and Tachibana, S. (2000). Involvement of polyamines in the chilling tolerance of cucumber cultivars. Plant Physiol. 124, 431-440. doi: 10.1104/pp.124.1.431

Shi, C., Qi, C., Ren, H. Y., Huang, A. X., Hei, S. M., and She, X. P. (2015). Ethylene mediates brassinosteroid-induced stomatal closure via $\mathrm{G} \alpha$ protein activated hydrogen peroxide and nitric oxide production in Arabidopsis. Plant J. 82, 280-301. doi: $10.1111 /$ tpj.12815

Shi, J., Fu, X. Z., Peng, T., Huang, X. S., Fan, Q. J., and Liu, J. H. (2010). Spermine pretreatment confers dehydration tolerance of citrus in vitro plants via modulation of antioxidative capacity and stomatal response. Tree Physiol. 30, 914-922. doi: 10.1093/treephys/tpq030

Sung, M. S., Chow, T. J., and Lee, T. M. (2011). Polyamine acclimation alleviates hyper salinity-induced oxidative stress in a marine green macroalga, Ulva fasciata, by modulation of antioxidative enzyme gene expression. J. Phycol. 47, 538-547. doi: 10.1111/j.1529-8817.2011. 00999.x

Szalai, G., Pap, M., and Janda, T. (2009). Light-induced frost tolerance differs in winter and spring wheat plants. J. Plant Physiol. 166, 1826-1831. doi: 10.1016/j.jplph.2009.04.016

Takahashi, S., and Murata, N. (2008). How do environmental stresses accelerate photoinhibition? Trends Plant Sci. 13, 178-182. doi: 10.1016/j.tplants.2008.01.005

Takahashi, T., and Kakehi, J. I. (2010). Polyamines: ubiquitous polycations with unique roles in growth and stress responses. Ann.Bot. 105, 1-6. doi: $10.1093 / \mathrm{aob} / \mathrm{mcp} 259$

Takano, A., Kakehi, J.-I., and Takahashi, T. (2012). Thermospermine is not a minor polyamine in the plant kingdom. Plant Cell Physiol. 53, 606-616. doi: 10.1093/pcp/pcs019

Tanou, G., Filippou, P., Belghazi, M., Job, D., Diamantidis, G., Fotopoulos, V., et al. (2012). Oxidative and nitrosative-based signalling and associated post-translational modifications orchestrate the acclimation of citrus plants to salinity stress. Plant J. 72, 585-599. doi: 10.1111/j.1365-313X.2012. 05100.x

Tanou, G., Ziogas, V., Belghazi, M., Christou, A., Filippou, P., Job, D., et al. (2014). Polyamines reprogram oxidative and nitrosative status and the proteome of citrus plants exposed to salinity stress. Plant Cell Environ. 37, 864-885. doi: $10.1111 /$ pce. 12204

Tassoni, A., Franceschetti, M., and Bagni, N. (2008). Polyamines and salt stress response and tolerance in Arabidopsis thaliana flowers. Plant Physiol. Biochem. 46, 607-613. doi: 10.1016/j.plaphy.2008.02.005

Tavladoraki, P., Rossi, M. N., Saccuti, G., Perez-Amador, M. A., Polticelli, F., Angelini, R., et al. (2006). Heterologous expression and biochemical characterization of a polyamine oxidase from Arabidopsis involved in polyamine back conversion. Plant Physiol. 141, 1519-1532. doi: 10.1104/pp.106.080911

Terzi, R., Kadioglu, A., Kalaycioglu, E., and Saglam, A. (2014). Hydrogen peroxide pretreatment induces osmotic stress tolerance by influencing osmolyte and abscisic acid levels in maize leaves. J. Plant Interact. 9, 559-565. doi: 10.1080/17429145.2013.871077

Triantaphylidès, C., Krischke, M., Hoeberichts, F. A., Ksas, B., Gresser, G., Havaux, M., et al. (2008). Singlet oxygen is the major reactive oxygen species involved in photooxidative damage to plants. Plant Physiol. 148, 960-968. doi: 10.1104/pp.108.125690

Urano, K., Yoshiba, Y., Nanjo, T., Ito, T., Yamaguchi-Shinozaki, K., and Shinozaki, K. (2004). Arabidopsis stress-inducible gene for arginine decarboxylase AtADC2 is required for accumulation of putrescine in salt tolerance. Biochem. Biophys. Res. Commun. 313, 369-375. doi: 10.1016/j.bbrc.2003.11.119

Vaahtera, L., Brosché, M., Wrzaczek, M., and Kangasjärvi, J. (2014). Specificity in ROS signaling and transcript signatures. Antioxid. Redox Signal. 21, 1422-1441. doi: 10.1089/ars.2013.5662

Velikova, V., Yordanov, I., and Edreva, A. (2000). Oxidative stress and some antioxidant systems in acid rain-treated bean plants: protective role of exogenous polyamines. Plant Sci. 151, 59-66. doi: 10.1016/S01689452(99)00197-1

Verma, S., and Mishra, S. N. (2005). Putrescine alleviation of growth in salt stressed Brassica juncea by inducing antioxidative defense system. J. Plant Physiol. 162, 669-677. doi: 10.1016/j.jplph.2004.08.008 
Yamasaki, H., and Cohen, M. F. (2006). NO signal at the crossroads: polyamineinduced nitric oxide synthesis in plants? Trends Plant Sci. 11, 522-524. doi: 10.1016/j.tplants.2006.09.009

Yoda, H., Hiroi, Y., and Sano, H. (2006). Polyamine oxidase is one of the key elements for oxidative burst to induce programmed cell death in tobacco cultured cells. Plant Physiol. 142, 193-206. doi: 10.1104/pp.106.080515

Yoda, H., Yamaguchi, Y., and Sano, H. (2003). Induction of hypersensitive cell death by hydrogen peroxide produced through polyamine degradation in tobacco plants. Plant Physiol. 132, 1973-1981. doi: 10.1104/pp.103.024737

Yoshida, M., Tomitori, H., Machi, Y., Hagihara, M., Higashi, K., Goda, H., et al. (2009). Acrolein toxicity: comparison with reactive oxygen species. Biochem. Biophys. Res. Commun. 378, 313-318. doi: 10.1016/j.bbrc.2008.11.054

Zhang, R. H., Li, J., Guo, S. R., and Tezuka, T. (2009). Effects of exogenous putrescine on gas exchange characteristics and chlorophyll fluorescence of NaCl-stressed cucumber seedlings. Photosynth. Res. 100, 155-162. doi: $10.1007 /$ s11120-009-9441-3
Zhu, J., Fu, X., Koo, Y. D., Zhu, J. K., Jenney, F. E. Jr., Adams, M. W., et al. (2007). An enhancer mutant of Arabidopsis salt overly sensitive 3 mediates both ion homeostasis and the oxidative stress response. Mol. Cell Biol. 27, 5214-5224. doi: 10.1128/MCB. 01989-06

Conflict of Interest Statement: The authors declare that the research was conducted in the absence of any commercial or financial relationships that could be construed as a potential conflict of interest.

Copyright (C) 2016 Gupta, Sengupta, Chakraborty and Gupta. This is an open-access article distributed under the terms of the Creative Commons Attribution License (CC $B Y)$. The use, distribution or reproduction in other forums is permitted, provided the original author(s) or licensor are credited and that the original publication in this journal is cited, in accordance with accepted academic practice. No use, distribution or reproduction is permitted which does not comply with these terms. 